\title{
Light Water Reactor Sustainability \\ Program \\ A Reference Plan for Control Room Modernization: Planning and Analysis Phase
}

September 2013
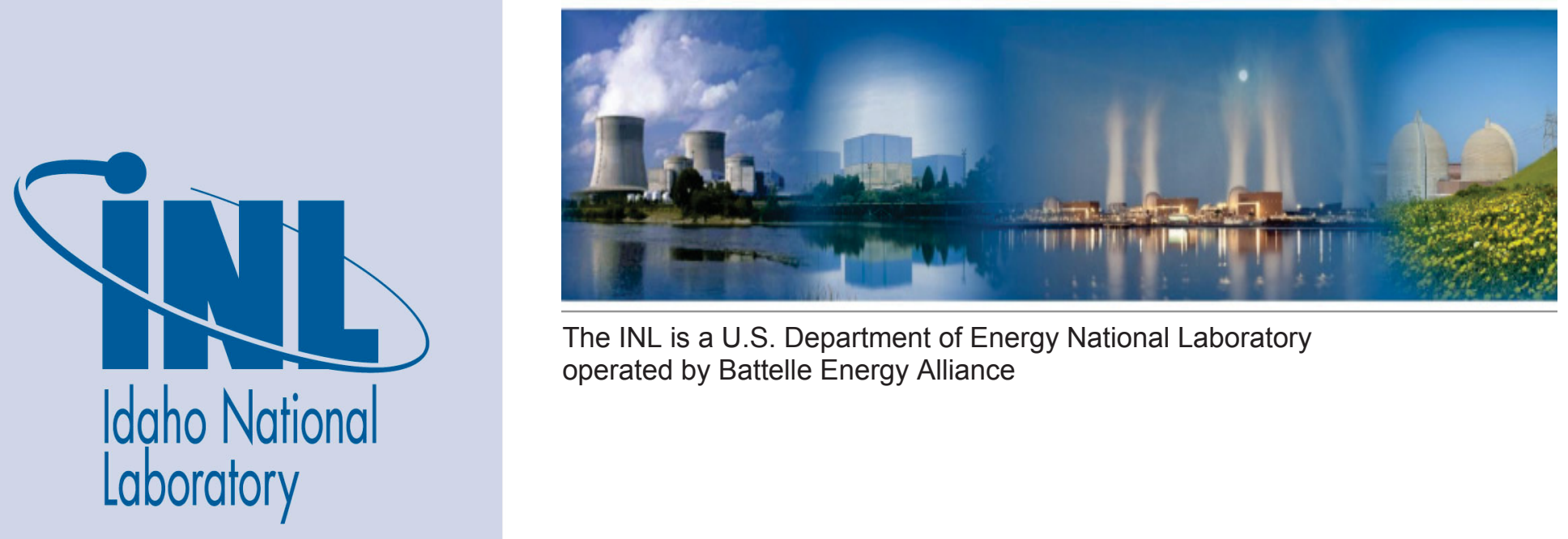

The INL is a U.S. Department of Energy National Laboratory operated by Battelle Energy Alliance 
INL/EXT-13-30109

\title{
Light Water Reactor Sustainability Program A Reference Plan for Control Room Modernization: Planning and Analysis Phase
}

\author{
Jacques Hugo \\ Ronald Boring \\ Lew Hanes \\ Ken Thomas
}

September 2013

\begin{abstract}
Idaho National Laboratory
Idaho Falls, Idaho 83415
\end{abstract}

http://www.inl.gov

\author{
Prepared for the \\ U.S. Department of Energy \\ Office of Nuclear Energy \\ Under DOE Idaho Operations Office \\ Contract DE-AC07-05ID14517
}




\section{DISCLAIMER}

This information was prepared as an account of work sponsored by an agency of the U.S. Government. Neither the U.S. Government nor any agency thereof, nor any of their employees, makes any warranty, expressed or implied, or assumes any legal liability or responsibility for the accuracy, completeness, or usefulness, of any information, apparatus, product, or process disclosed, or represents that its use would not infringe privately owned rights. References herein to any specific commercial product, process, or service by trade name, trade mark, manufacturer, or otherwise, does not necessarily constitute or imply its endorsement, recommendation, or favoring by the U.S. Government or any agency thereof. The views and opinions of authors expressed herein do not necessarily state or reflect those of the U.S. Government or any agency thereof. 



\section{EXECUTIVE SUMMARY}

The U.S. Department of Energy's Light Water Reactor Sustainability (LWRS) program is collaborating with a U.S. nuclear utility to bring about a systematic fleet-wide control room modernization. To facilitate this upgrade, a new distributed control system (DCS) is being introduced into the control rooms of these plants. The DCS will upgrade the legacy plant process computer and emergency response facility information system. In addition, the DCS will replace an existing analog turbine control system with a display-based system.

With technology upgrades comes the opportunity to improve the overall human-system interaction between the operators and the control room. To optimize operator performance, the LWRS Control Room Modernization research team followed a human-centered approach published by the U.S. Nuclear Regulatory Commission. NUREG-0711, Rev. 3, Human Factors Engineering Program Review Model (O'Hara et al., 2012), prescribes four phases for human factors engineering. This report provides examples of the first phase, Planning and Analysis. The three elements of Planning and Analysis in NUREG-0711 that are most crucial to initiating control room upgrades are:

- Operating Experience Review: Identifies opportunities for improvement in the existing system and provides lessons learned from implemented systems.

- Function Analysis and Allocation: Identifies which functions at the plant may be optimally handled by the DCS versus the operators.

- Task Analysis: Identifies how tasks might be optimized for the operators.

Each of these elements is covered in a separate chapter. Examples are drawn from workshops with reactor operators that were conducted at the LWRS Human System Simulation Laboratory (HSSL) and at the respective plants. The findings in this report represent generalized accounts of more detailed proprietary reports produced for each of the utility's plants. The goal of this LWRS report is to disseminate the technique and provide examples sufficient to serve as a template for other utilities' projects for control room modernization. 


\section{ACKNOWLEDGMENTS}

This report was made possible through funding by the U.S. Department of Energy (DOE) Light Water Reactor Sustainability (LWRS) Program. We are grateful to Richard Reister of the DOE and Bruce Hallbert and Kathryn McCarthy of the Idaho National Laboratory (INL) for championing this effort. Additional funding was made possible by the utility for which the technical work in this report was conducted. We are especially grateful to the program management, reactor operator, and simulator staff at the respective plants who generously contributed their time and talents to this initial phase of control room modernization. 


\section{CONTENTS}

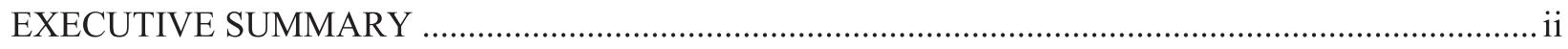

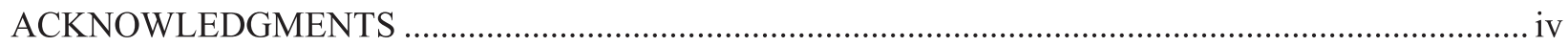

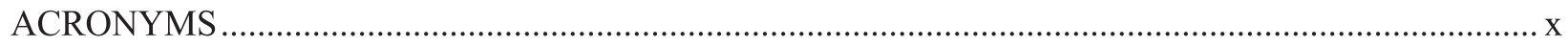

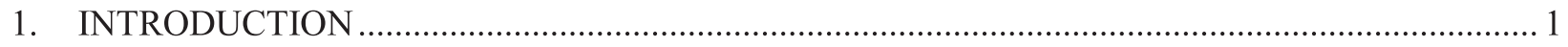

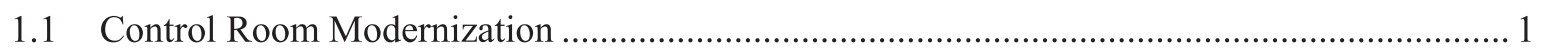

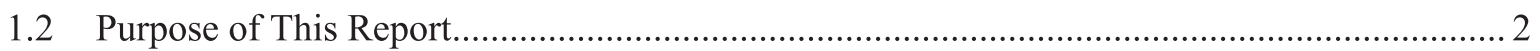

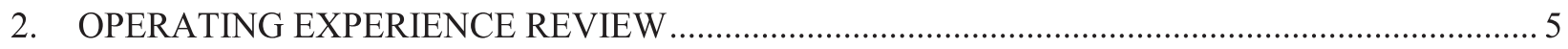

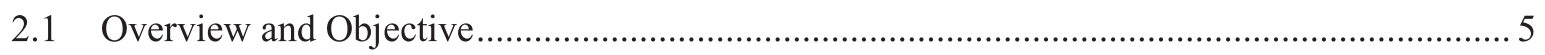

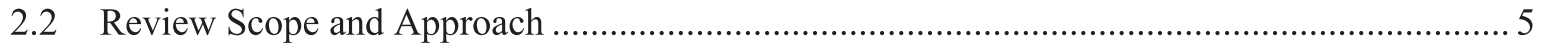

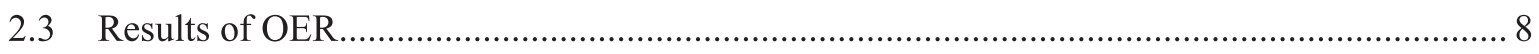

3. FUNCTIONAL REQUIREMENTS ANALYSIS AND FUNCTION ALLOCATION..................... 11

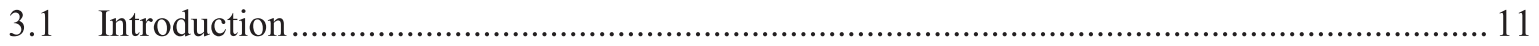

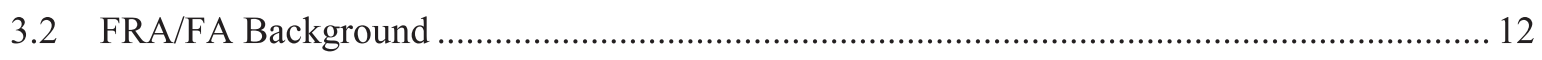

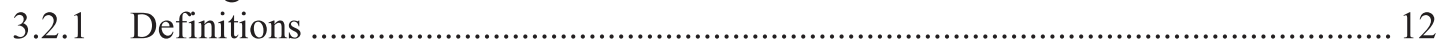

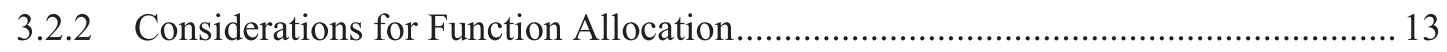

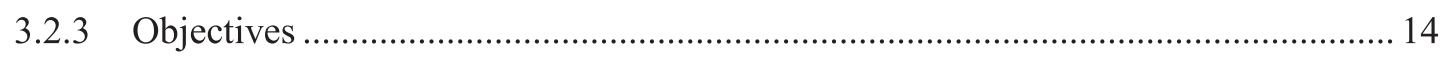

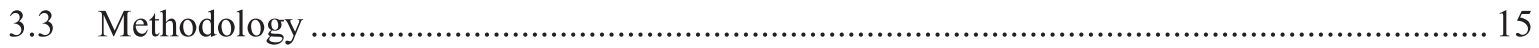

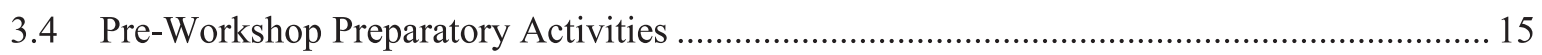

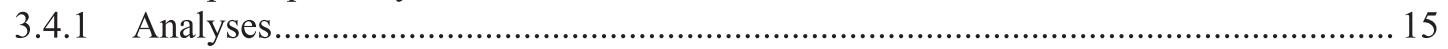

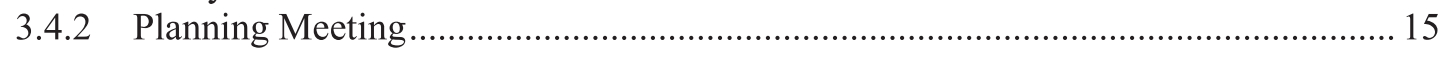

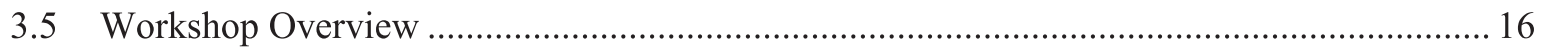

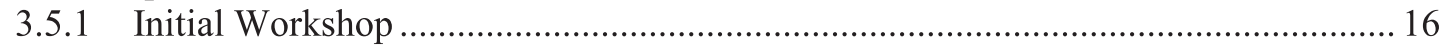

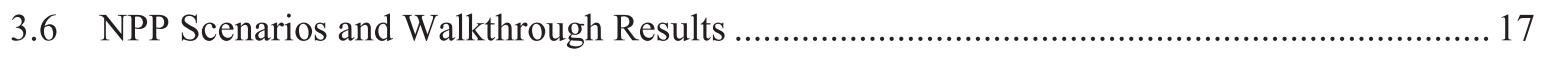

3.7 Functional Requirements Analysis Summary …......................................................... 21

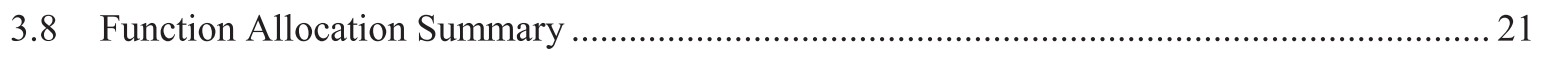

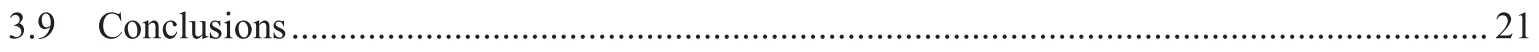

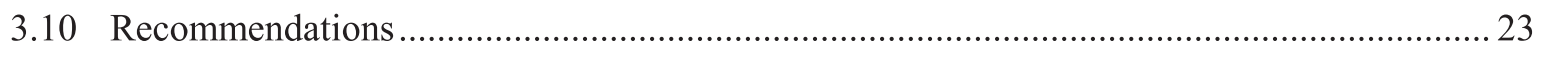

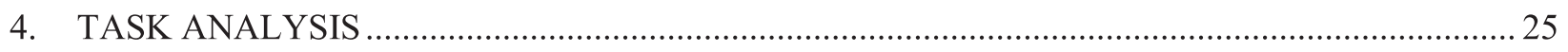

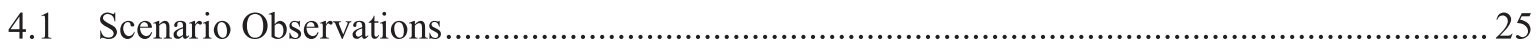

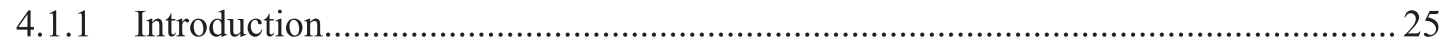

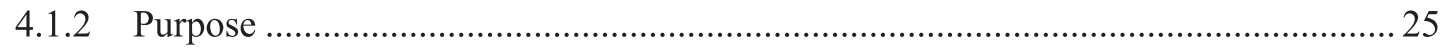

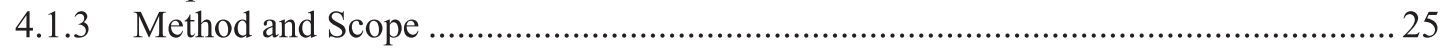

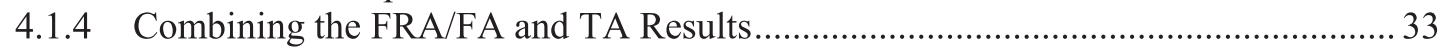

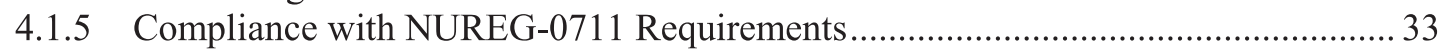

4.1.6 Additional Considerations for HFE Aspects of Plant Modifications.......................... 36

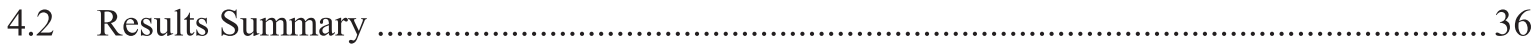

4.2.1 Potential Enhancements as Part of Control Room Modernization ............................ 37 


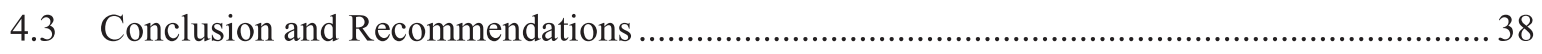

5. NEXT STEPS: DESIGN, VERIFICATION AND VALIDATION, AND

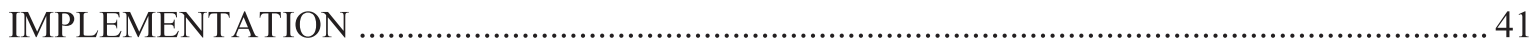

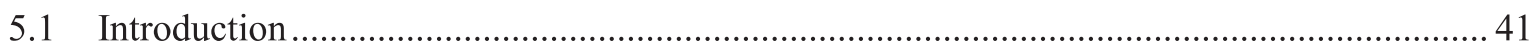

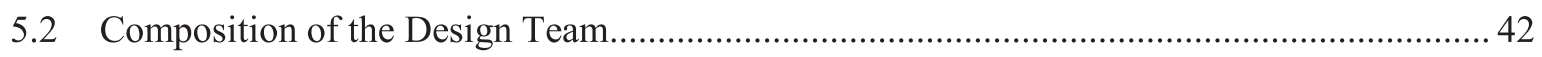

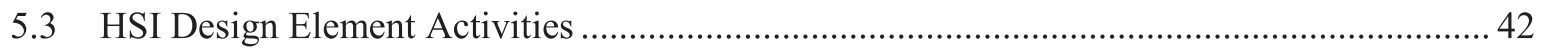

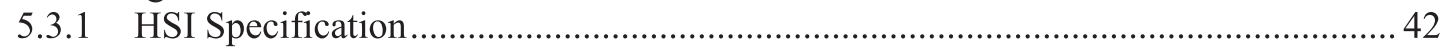

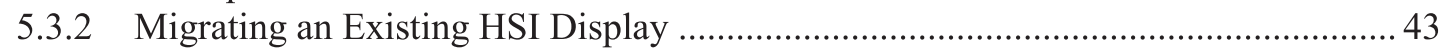

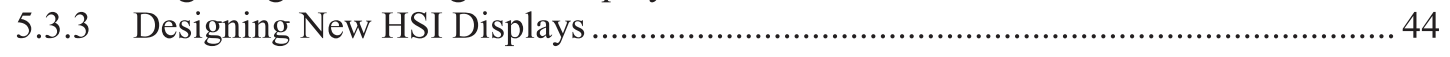

5.4 Human Factors Verification and Validation of the HSI.................................................... 47

5.5 Design Implementation of the DCS HSI.......................................................................... 49

5.6 Sample Plan for Design, V\&V, and Implementation Phases .......................................... 49

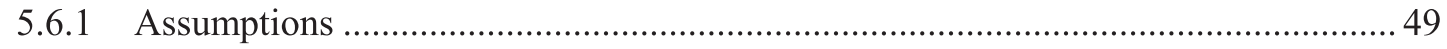

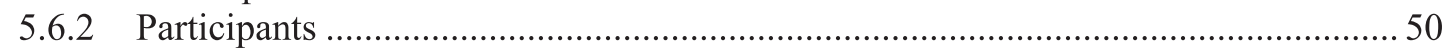

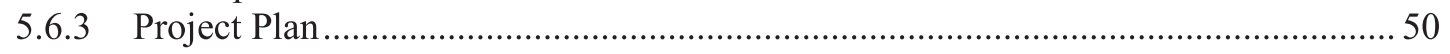

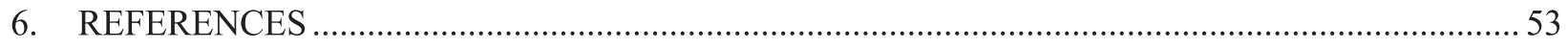




\section{FIGURES}

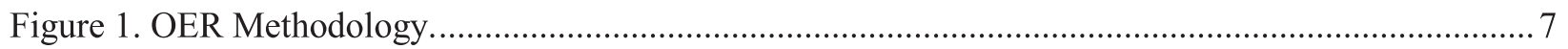

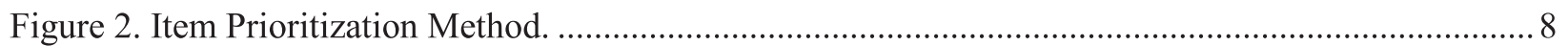

Figure 3. The Human System Simulation Laboratory at the Idaho National Laboratory.......................... 11

Figure 4. Scenario 1 Operational Sequence Diagram. …....................................................................... 30

Figure 5. Required Information for DCS Display Specification......................................................... 43

Figure 6. Flow Diagram for Developing New HSI Displays for DCS. ................................................. 46 


\section{TABLES}

Table 1. HFE Phases Covered in NUREG-0711, Rev. 3 ...................................................................... 1

Table 2. Terms with Human Error Indicated That Were Used for Searching the Utility's OE Databases.

Table 3. Relation between HFE Elements and Item Classification. ....................................................... 7

Table 4. Example HFE OER Item Summary and Status Database....................................................... 9

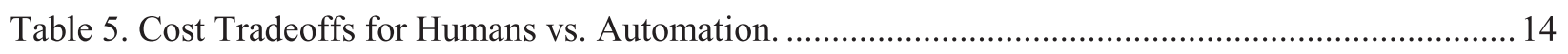

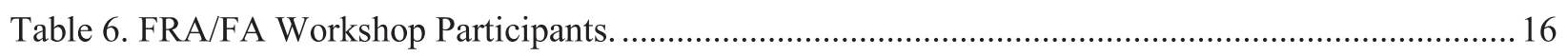

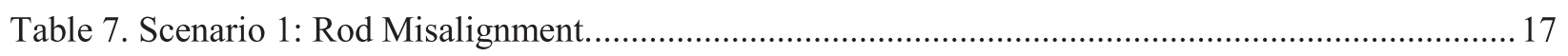

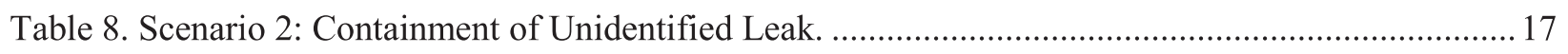

Table 9. Scenario 3: Double-Ended Break on Cold Leg....................................................................... 19

Table 10. Scenario 4: Small Steam Generator Leak. ................................................................................ 20

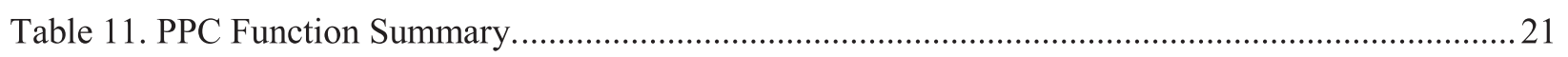

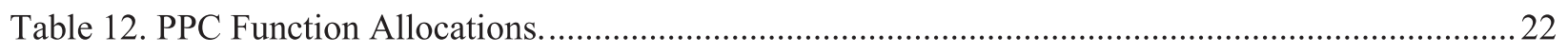

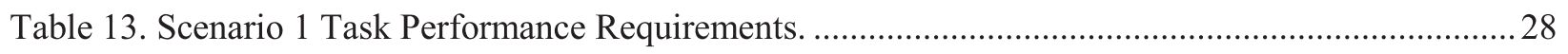

Table 14. Graphical Conventions Used in Operational Sequence Diagrams...........................................29

Table 15. Human Factors Recommendations for PPC and TCS Upgrades. ............................................ 40

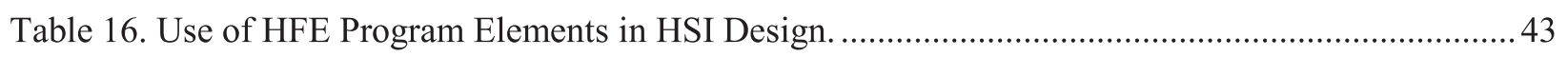

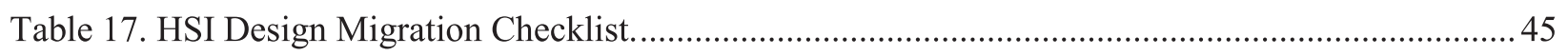

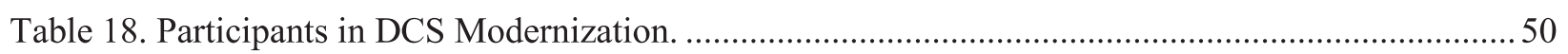

Table 19. Project Plan for Design, V\&V, and Implementation for DCS HSI in the Main Control Room. 


\section{ACRONYMS}

\begin{tabular}{|c|c|}
\hline $\mathrm{AE}$ & Architect Engineering \\
\hline AFD & Axial Flux Difference \\
\hline AS & Automation System \\
\hline BWR & Boiling Water Reactor \\
\hline CFR & Code of Federal Regulations \\
\hline $\mathrm{CR}$ & Control Room \\
\hline $\mathrm{CS}$ & Computer System Engineering \\
\hline DAS & Diverse Actuation System \\
\hline DC & DCS Vendor \\
\hline DCS & Distributed Control System \\
\hline DOE & Department of Energy \\
\hline DRPI & Digital Rod Position Indication \\
\hline EOF & Emergency Operations Facility \\
\hline EPRI & Electrical Power Research Institute \\
\hline ERFIS & Emergency Response Facility Information System \\
\hline ESFAS & Engineered Safety Feature Actuation System \\
\hline FA & Function Allocation \\
\hline FRA & Functional Requirements Analysis \\
\hline GPM & Gallons per Minute \\
\hline HA & Human Action \\
\hline $\mathrm{HF}$ & Human Factors \\
\hline HFE & Human Factors Engineering \\
\hline HP & High Pressure \\
\hline HRA & Human Reliability Analysis \\
\hline HS & HSI Vendor \\
\hline HSI & Human-System Interface \\
\hline HSSL & Human System Simulation Laboratory \\
\hline $\mathrm{I} \& \mathrm{C}$ & Instrumentation and Controls \\
\hline IC & Instrumentation and Control Engineering \\
\hline IEEE & Institute of Electrical and Electronics Engineers \\
\hline INL & Idaho National Laboratory \\
\hline ISO & International Standards Organization \\
\hline ISV & Integrated System Validation \\
\hline LCS & Local Control Station \\
\hline LOCA & Loss of Coolant Accident \\
\hline LP & Low Pressure \\
\hline LWRS & Light Water Reactor Sustainability \\
\hline MCR & Main Control Room \\
\hline NPP & Nuclear Power Plant \\
\hline $\mathrm{NRC}$ & U.S. Nuclear Regulatory Commission \\
\hline NUREG & Nuclear Regulatory Document \\
\hline $\mathrm{OAC}$ & Operator at the Controls \\
\hline $\mathrm{OE}$ & Operating Event \\
\hline OER & Operating Experience Review \\
\hline OSA & Operational Sequence Analysis \\
\hline OSD & Operational Sequence Diagram \\
\hline PM & Project Management \\
\hline $\mathrm{PO}$ & Plant Operations \\
\hline
\end{tabular}




$\begin{array}{ll}\text { PPC } & \text { Plant Process Computer } \\ \text { PRA } & \text { Probabilistic Risk Assessment } \\ \text { PT } & \text { Personnel Training } \\ \text { PW } & \text { Procedure Writers } \\ \text { PWR } & \text { Pressurized Water Reactor } \\ \text { RHR } & \text { Reactor Heat Removal } \\ \text { RCS } & \text { Reactor Cooling System } \\ \text { RMS } & \text { Radiation Monitoring System } \\ \text { RO } & \text { Reactor Operator } \\ \text { RSF } & \text { Remote Shutdown Facility } \\ \text { RVLIS } & \text { Reactor Vessel Level Indication System } \\ \text { SE } & \text { Systems Engineering } \\ \text { SG } & \text { Steam Generator } \\ \text { SPDS } & \text { Safety Parameter Display System } \\ \text { SRO } & \text { Senior Reactor Operator } \\ \text { TA } & \text { Task Analysis } \\ \text { Tavg } & \text { Average Temperature } \\ \text { TCS } & \text { Turbine Control System } \\ \text { Tref } & \text { Reference Temperature } \\ \text { TSC } & \text { Technical Support Center } \\ \text { VCT } & \text { Volume Control Tank } \\ \text { VDT } & \text { Video Display Terminal } \\ \text { VDU } & \text { Visual Display Unit } \\ \text { V\&V } & \text { Verification and Validation } \\ & \end{array}$




\section{INTRODUCTION}

\subsection{Control Room Modernization}

This report summarizes collaboration between the U.S. Department of Energy's Light Water Reactor Sustainability (LWRS) program and an energy utility that is conducting a fleet-wide modernization of the main control rooms (MCRs) at its three nuclear power plants. To facilitate this upgrade, a new distributed control system (DCS) is being introduced into the control rooms of these plants. The DCS will upgrade the legacy plant process computer (PPC) and emergency response facility information system (ERFIS). In addition, the DCS will replace an existing analog turbine control system (TCS) with a display-based system. The DCS will feature digital equivalents of the former analog instrumentation and control (I\&C) that meet and exceed their current functionality. In addition to like-for-like digital equivalents, the DCS will include displays and functionalities that enable control room staff to:

- Access important trend information quickly to better anticipate and manage emerging conditions

- Perform calculations that would otherwise be done manually

- Access prioritized alarm lists to respond to plant transients more quickly

- Obtain helpful checklists that are used to augment paper procedures.

The DOE LWRS Control Room Modernization pilot project and its research staff at the Idaho National Laboratory (INL) are providing systematic studies and evaluations of modernization technologies prior to implementation in plant main control rooms. A particular emphasis of these efforts is on human factors engineering, which studies ways to enhance reactor operator performance through improved humansystem interfaces (HSIs).

NUREG-0711, Rev. 3, Human Factors Engineering Program Review Model (O'Hara et al., 2012) prescribes four phases for human factors engineering (HFE). Each phase consists of one or more elements. Each element contains a description of the review criteria applied by the U.S. Nuclear Regulatory Commission (U.S. NRC) HFE staff to assess the acceptability of an applicant's submittal regarding safe plant operation. Several phases of the HFE process necessary for control room upgrades are depicted in Table 1.

Table 1. HFE Phases Covered in NUREG-0711, Rev. 3.

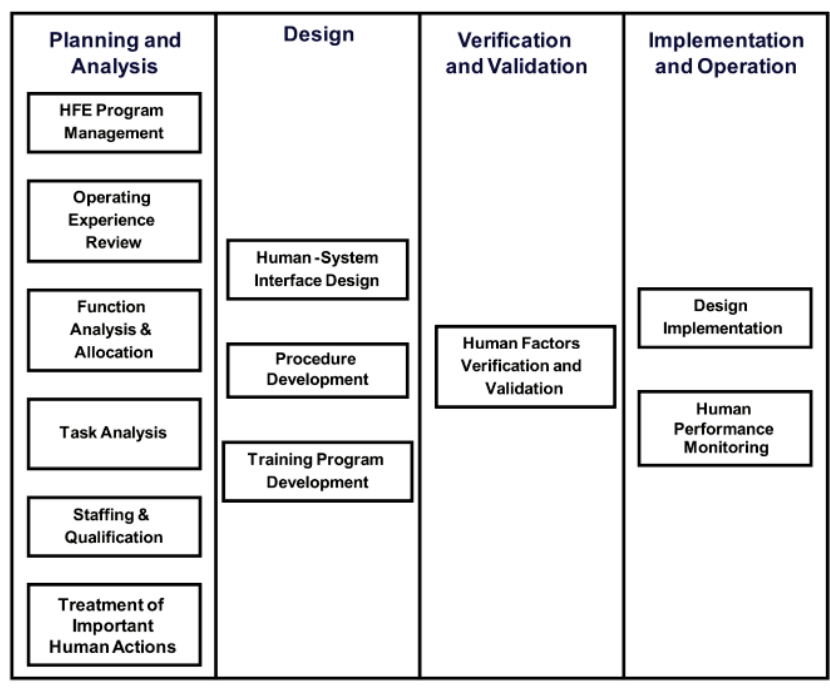


Note that NUREG-0711 is meant to support the initial licensing of plant technologies. It is anticipated that many digital upgrades will mimic the functionality of analog systems they are replacing and will not require license amendment for such modernization. Additionally, most modifications specifically are not targeted at modifications to Class $1 \mathrm{E}$ safety systems at the plant and would not fall under a requirement for license modification. However, the HFE process outlined in NUREG-0711 represents industry best practice and serves as a template for control room modifications, even if those modifications and upgrades do not explicitly require a license amendment under 10 Code of Federal Regulations (CFR) Part 50, "Domestic Licensing of Production and Utilization Facilities," Section 59, "Changes, Tests and Experiments" (U.S. NRC, 2000).

In support of upgrading the control systems at utility's plants, the LWRS Control Room Modernization pilot project is conducting a modernization program that follows NUREG-0711 guidelines. Through a series of workshops with plant reactor operators conducted both at the DOE's Human Systems Simulation Laboratory (HSSL) and at the respective plants, LWRS researchers are leading a first-of-a-kind effort to apply a comprehensive HFE process to control room modernization in the U.S. A graded approach is being applied to the process, whereby the effort is focused on the most crucial phases of NUREG-0711 that support control room modernization that does not explicitly require a license amendment. These main phases of HFE for control room modernization and their accompanying goals are listed in Table 2.

Table 2. Main Phases of Human Factors Engineering and Underlying Goals.

\begin{tabular}{|c|c|c|c|c|c|c|c|c|c|}
\hline & $\begin{array}{l}\text { Operating } \\
\text { Experience } \\
\text { Review }\end{array}$ & $\rightarrow$ & $\begin{array}{l}\text { Function } \\
\text { Allocation }\end{array}$ & $\rightarrow$ & $\begin{array}{l}\text { Task } \\
\text { Analysis }\end{array}$ & $\rightarrow$ & $\begin{array}{l}\text { Design } \\
\text { Activities }\end{array}$ & $\rightarrow$ & $\begin{array}{l}\text { Verification } \\
\text { and } \\
\text { Validation }\end{array}$ \\
\hline 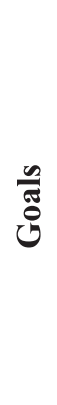 & $\begin{array}{l}\text { What happened } \\
\text { before? Identify } \\
\text { where existing } \\
\text { system could be } \\
\text { improved and } \\
\text { where similar } \\
\text { systems have } \\
\text { provided } \\
\text { relevant } \\
\text { insights. }\end{array}$ & & $\begin{array}{l}\text { What is system } \\
\text { vs. operator } \\
\text { controlled? } \\
\text { Identify } \\
\text { opportunities to } \\
\text { improve } \\
\text { performance by } \\
\text { indentifying } \\
\text { modifiable } \\
\text { functions. }\end{array}$ & & $\begin{array}{l}\text { What can be } \\
\text { changed? } \\
\text { Define } \\
\text { information } \\
\text { and control } \\
\text { needs for } \\
\text { operators to } \\
\text { perform new } \\
\text { and existing } \\
\text { functions. }\end{array}$ & & $\begin{array}{l}\text { What's the } \\
\text { new design? } \\
\text { Develop } \\
\text { conceptual } \\
\text { designs for } \\
\text { the HSIs. }\end{array}$ & & $\begin{array}{l}\text { Does it work? } \\
\text { Test the } \\
\text { designs and } \\
\text { make sure all } \\
\text { required } \\
\text { information } \\
\text { and controls are } \\
\text { there and work. }\end{array}$ \\
\hline
\end{tabular}

\subsection{Purpose of This Report}

This report covers the first phase of control room modernization, namely the Planning and Analysis phase. The three elements of Planning and Analysis in NUREG-0711 that are most crucial to initiating control room upgrades are:

- Operating Experience Review: The operating experience review (OER) examines experience using the existing system to be upgraded and similar systems and technologies already in place. The OER identifies opportunities for improvement in the existing system and provides lessons learned from implemented systems.

- Function Analysis and Allocation: This element actually includes two separate activities - functional requirements analysis (FRA) and function allocation (FA). The goal of FRA/FA is to identify which 
functions at the plant may be automated vs. manually operated. Automation in this case refers not just to the control of the system but also the information provided by the system. Since control automation would most likely require license amendment, a particular emphasis on FRA/FA is to identify where information collection may be automated in the sense of brought together in a consolidated display in order to minimize the need for the operator to gather that information from disparate sources.

- Task Analysis: The goal of task analysis (TA) is to determine how operator tasks are currently performed and to identify potential areas for improvement.

By agreement with the utility project management team, two elements were excluded from the process for the Planning and Analysis phase. These out-of-scope elements were:

- Staffing and Qualifications: These are not currently subject to change due to any modifications to the PPC or TCS.

- Treatment of Important Human Actions (formerly Human Reliability Analysis): The safety impact of human actions was also determined not to change due to any modifications to the PPC or TCS.

This report provides illustrations of OER (Chapter 2), FRA/FA (Chapter 3), and TA (Chapter 4) for how the Planning and Analysis can be conducted in support of control room modernization. Additionally, a plan is provided in Chapter 5 to support the remaining phases of NUREG-0711-Design, Verification and Validation $(\mathrm{V} \& \mathrm{~V})$, and Implementation. The approach and findings in this report are derived from a real Planning and Analysis exercise conducted with a specific utility and its three nuclear power plants. Plants A and C are both single three-loop pressurized water reactors (PWRs) designed by Westinghouse. Plant B consists of two Mark I boiling water reactors (BWRs) designed by General Electric.

The findings in this report represent generalized accounts of more detailed proprietary reports produced for the utility for each plant. The goal of this LWRS report is to disseminate the technique and provide examples sufficient to serve as a template for other utilities' projects for control room modernization. As the further phases of the HFE process are completed, they will be disseminated as joint reports with the Electrical Power Research Institute (EPRI). The join LWRS/EPRI reports will provide relevant document templates, step-by-step guidance, and lessons learned for control room modernization across the U.S. nuclear industry. The first joint branded report is this series is anticipated to appear in early fiscal year 2014. 


\section{OPERATING EXPERIENCE REVIEW}

\subsection{Overview and Objective}

An HFE Operating Experience Review (OER) was performed as part of the plants' PPC and TCS upgrade project. The methodology applied is based on NUREG-0711 (O'Hara et al., 2012) review criteria and guidance in EPRI 1010042 (2005). This chapter summarizes the OER results of applying the methodology.

The objective of this OER is to obtain, analyze, and make available for application HFE-related safety and availability events, issues and information on past operational performance at the specific plants being updated, other nuclear power generating plants in the United States and in Europe, and from a few additional process control industries. The results provide a basis for improving aspects of the control room design involving the PPC and TCS. This will help reduce human errors and their impact on risk and reliability of plant operation. The objective is to identify positive features of the existing design while also capturing any lessons learned on operating the existing systems.

The OER is limited to identifying and analyzing operating experience related to the events, scenarios, equipment and systems involving the planned PPC and TCS upgrades for the plants' main control rooms. The OER results were applied to activities associated with the FRA, FA, and TA elements. Some of the issues identified during the $\mathrm{OE}$ are applicable to subsequent elements in the design process, e.g., HSI design and V\&V. Design issues are identified in this chapter, but no action is taken to address them during this preliminary stage of modernization. Actions regarding these issues will be taken in a future HFE project.

The OER involved obtaining and analyzing HFE-related safety and availability issues and information from the following sources:

- Related plants and systems including the utility's fleet of nuclear plants

- Recognized industry HFE issues identified in NUREG/CR-6400 (U.S. NRC, 1995) and the 14 Volumes in NUREG-1275 with special attention given to Volumes 8 (1992) and 11 (2005)

- Related HFE technology that is new with the upgrades, e.g., automation

- Issues identified by plant control room operators during interviews and surveys

- Risk-Important Human Actions (HAs) that are different or where errors have occurred

This chapter describes the review scope and approach taken to perform the OER (Section 2.2), OER item summary and status (Section 2.3), and conclusions (Section 2.4). It must be noted that issues identified are not specifically safety concerns. In all cases, issues identified are simply areas for improvement, not overt risks (Ulrich et al., 2012). A goal of control room modernization is to make tasks easier to do and thereby build on already high safety standards at the plants.

\subsection{Review Scope and Approach}

The OER involved the following activities: 
Table 2. Terms with Human Error Indicated That Were Used for Searching the Utility's OE Databases.

\begin{tabular}{|c|c|}
\hline Turbine Generator & HFE Terms (Continued) \\
\hline$\overline{\text { Extraction steam and augmented off gas }}$ & Legend error \\
\hline Electrical distribution & Location error \\
\hline Generator & Mode error \\
\hline HP turbine & Monitoring error \\
\hline LP turbine & Navigation \\
\hline Loss of off-site power & Reading error \\
\hline Turbine & Situation awareness \\
\hline Turbine Control System & Stress \\
\hline \multirow[t]{2}{*}{ Turbine Trips } & Verify error \\
\hline & Vigilance error \\
\hline Plant Computer & Workload \\
\hline Integrated Plant Computer & Workload error \\
\hline \multicolumn{2}{|l|}{ Operator Aid Computer } \\
\hline Plant Computer & General Terms \\
\hline \multirow[t]{2}{*}{ SPDS } & Alarms \\
\hline & Annunciator \\
\hline HFE Terms & Feedwater system \\
\hline Automation & Axial flux \\
\hline Cognitive error & Fluxmap \\
\hline Color coding & Calorimetric \\
\hline Control error & Communication \\
\hline Control selection error & Condenser/condensate system \\
\hline Data entry error & Conduct of work \\
\hline Data input & Containment sump \\
\hline Design error & Control \\
\hline Diagnostic error & Historical information \\
\hline Decision-making & Labeling \\
\hline Demarcation & Loss of RCS inventory \\
\hline Detection & Loss of RHR function Mimics \\
\hline Diagnosis error & Mispositioning \\
\hline Display & Operator action \\
\hline Display selection error & Planning \\
\hline Ergonomics & Primary containment \\
\hline Fixation & Procedure \\
\hline Human error & Reactor vessel \\
\hline Human factors & Rods \\
\hline Human performance & Safeguards \\
\hline Human-machine interface & Service water system \\
\hline Human-system interface & Steam cycle \\
\hline Interpretation & Touch screen \\
\hline \multirow[t]{3}{*}{ Keyhole effect } & Valve lineup \\
\hline & Work practices \\
\hline & Work processes \\
\hline
\end{tabular}


- Identifying the technological changes associated with the PPC and TSC upgrades that could affect operator functions and tasks (based on review of the plants' display requirements specifications and discussions with the utility's engineering personnel)

- Selecting the sources for the OE information (as noted in Section 2.1)

- Selecting key terms for database and other searches (see example in Table 2)

- Developing and administering an OE survey plant control room operators

- Reviewing and analyzing the information provided by the sources, and summarizing the results for application in the FRA, FA, and TA element activities

The OER methodology shown in Figure 1 was applied. The OE sources were analyzed, and relevant items classified according to the element with which each was associated (see Table 3). Each item was prioritized following the procedure shown in Figure 2. The items were then documented as shown in Table 4 in Section 2.3. This listing of prioritized items permits tracking of the disposition of each item thus ensuring the knowledge is available to the HFE team.

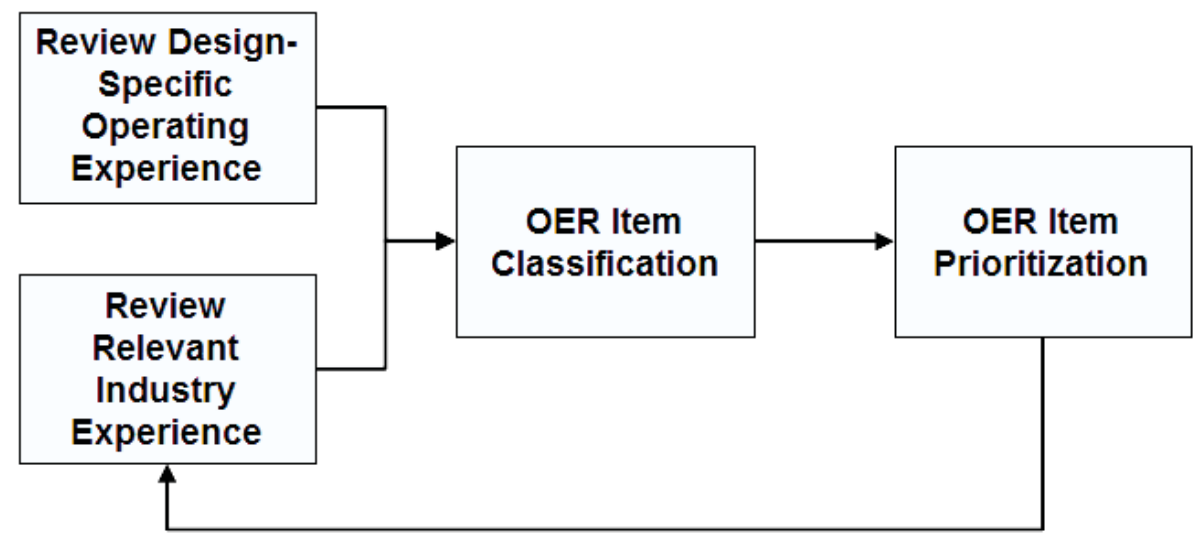

Iterate as necessary

Figure 1. OER Methodology.

Table 3. Relation between HFE Elements and Item Classification.

\begin{tabular}{|l|l|}
\hline \multicolumn{1}{|c|}{ HFE Element } & \multicolumn{1}{c|}{ OER Item Classification } \\
\hline \multirow{4}{*}{$\begin{array}{l}\text { Functional Requirements Analysis and } \\
\text { Function Allocation }\end{array}$} & Basis for initial requirements \\
\cline { 2 - 2 } $\begin{array}{l}\text { Task Analysis, Human Reliability } \\
\text { Analysis, and Staffing/Qualifications }\end{array}$ & Basis for initial allocations \\
\cline { 2 - 2 } & Identification of need for modifications \\
\cline { 2 - 2 } $\begin{array}{l}\text { Human-System Interface, Procedures, } \\
\text { and Training Development }\end{array}$ & Problematic operations and tasks \\
\cline { 2 - 2 } & Instances of staffing shortfalls \\
\cline { 2 - 2 } $\begin{array}{l}\text { Human Factors Verification and } \\
\text { Validation }\end{array}$ & Potential design solutions \\
\cline { 2 - 2 } & Potential design issues \\
\cline { 2 - 2 } & Tasks to be evaluated \\
\cline { 2 - 2 } & Event and scenario selection \\
\cline { 2 - 2 } & Performance measure selection \\
\cline { 2 - 2 } & Issue resolution verification \\
\hline
\end{tabular}




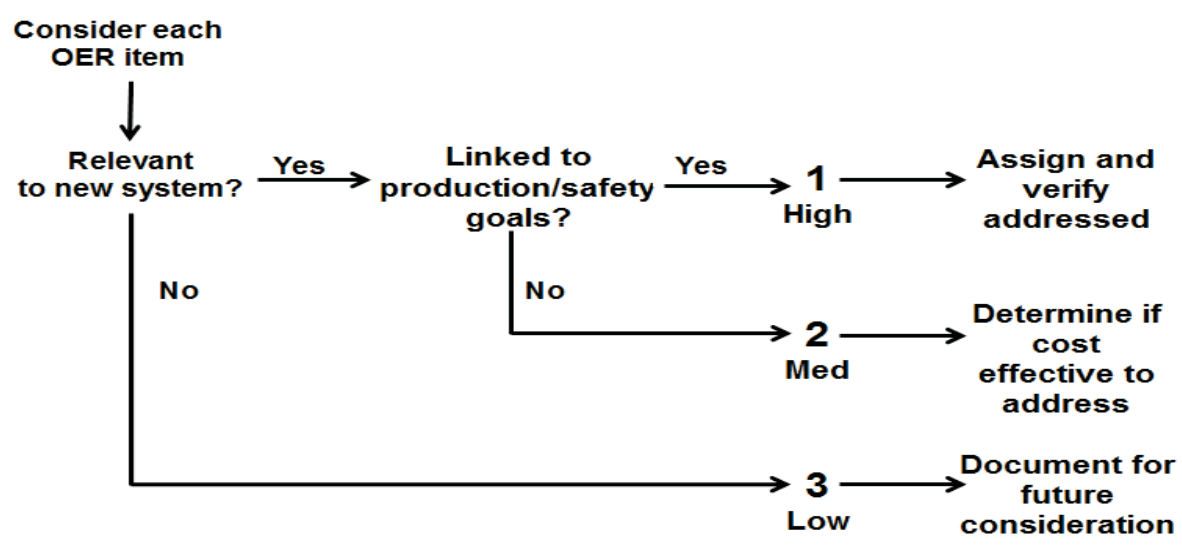

Figure 2. Item Prioritization Method.

\subsection{Results of OER}

The OER identified 32 items, excerpts of which are summarized in Table 4. Each item is numbered for tracking purposes, prioritized (only "1-High Priority" items are shown), described, referenced to the source of the information (more specific sources would be found in the actual summary table), and catalogued for immediate or future action. In the actual OER report, separate appendices are provided for each OER item in order to provide more detailed information to understand the nature of the item and possible mitigations. Although the emphasis of the OER was to identify items pertaining to the FRA/FA and TA elements, many of the OEs relate partly or entirely to elements applied later during design, e.g., the HSI design. Although these issues are identified in the OER, no action is taken regarding their disposition. Actions regarding these issues will be taken in a future HFE project. 
Table 4. Example HFE OER Item Summary and Status Database.

\begin{tabular}{|c|c|c|c|c|}
\hline No./Title & Priority & Description and Summary & Source & Disposition \\
\hline $\begin{array}{l}\text { 1/Plant Process } \\
\text { Computer } \\
\text { Monitor for } \\
\text { Operator } \\
\text { at Controls }\end{array}$ & $\begin{array}{l}\text { 1/FRA, TA, } \\
\text { HSI Design }\end{array}$ & $\begin{array}{l}\text { Changes need to be made to enhance the } \\
\text { ability of the operator at the controls (OAC) to } \\
\text { monitor reactivity changes. Currently PPC } \\
\text { information such as the accurate indication for } \\
\text { total core flow, heat balance, and position on } \\
\text { the power to flow map is not available to the } \\
\text { OAC. This hampers reactivity changes since } \\
\text { power changes are based on heat balance or } \\
\text { flow. This requires the OAC to stop the power } \\
\text { change to monitor these parameters on the } \\
\text { PPC. This creates the potential to miss target } \\
\text { power levels as requested by the reactor } \\
\text { engineer. A solution would be to make this } \\
\text { information available to the OAC at the } \\
\text { boards. }\end{array}$ & $\begin{array}{l}\text { Operator } \\
\text { surveys }\end{array}$ & Active \\
\hline $\begin{array}{l}\text { 2/Human Error in } \\
\text { Changing Main } \\
\text { Turbine Load }\end{array}$ & $\begin{array}{l}\text { 1/HSI } \\
\text { Design }\end{array}$ & $\begin{array}{l}\text { During the refueling outage plant startup, the } \\
\text { control room crew raised main turbine load at } \\
\text { a rate of } 10 \% \text { per minute rather than the } \\
\text { briefed rate of } 10 \% \text { per hour during Digital } \\
\text { Electro Hydraulic Control System testing. } \\
\text { This occurred because the plant operator did } \\
\text { not change the ramp rate to percent per hour } \\
\text { from percent per minute prior to initiating the } \\
\text { turbine load ascension. }\end{array}$ & $\begin{array}{l}\text { Outside } \\
\text { Source: INPO } \\
\text { Database and } \\
\text { EPRI Reports }\end{array}$ & $\begin{array}{l}\text { Deferred to } \\
\text { HSI Design } \\
\text { Phase }\end{array}$ \\
\hline $\begin{array}{l}\text { 3/Miscellaneous } \\
\text { Problems Related } \\
\text { to Control Board } \\
\text { and Display } \\
\text { Design during } \\
\text { Modernization of } \\
\text { Plant in Finland } \\
\end{array}$ & $\begin{array}{l}\text { 1/FRA, FA, } \\
\text { TA, HSI } \\
\text { Design }\end{array}$ & $\begin{array}{l}\text { HFE reviews of the planned turbine system } \\
\text { upgrade for turbine monitoring and control to } \\
\text { a Finnish plant identified } 10 \text { deficiencies } \\
\text { related to design, e.g., annunciators and } \\
\text { alarms, mimics, trends, pop-up menus, } \\
\text { predictive information, display design and } \\
\text { readability. }\end{array}$ & $\begin{array}{l}\text { Outside } \\
\text { Source: OE } \\
\text { from } \\
\text { European } \\
\text { Nuclear Plant } \\
\text { Upgrade } \\
\text { Projects } \\
\end{array}$ & Active \\
\hline $\begin{array}{l}\text { 4/Problems in } \\
\text { Configuring } \\
\text { Displays in } \\
\text { Aviation }\end{array}$ & $\begin{array}{l}\text { 1/HSI } \\
\text { Design }\end{array}$ & $\begin{array}{l}\text { Several reports of flight crews having } \\
\text { difficulty in zooming and panning to } \\
\text { configure the display for readability. } \\
\text { Information may be missed because it is out of } \\
\text { view, or workload may be increased because } \\
\text { of the task of configuring display. Also, } \\
\text { screen is hard to use under different lighting } \\
\text { conditions, and difficult to access related } \\
\text { information. }\end{array}$ & $\begin{array}{l}\text { Outside } \\
\text { Source: OE } \\
\text { from } \\
\text { Aviation }\end{array}$ & $\begin{array}{l}\text { Deferred to } \\
\text { HSI Design } \\
\text { Phase }\end{array}$ \\
\hline $\begin{array}{l}\text { 5/Failures in } \\
\text { Operator } \\
\text { Awareness to } \\
\text { Recognize Off- } \\
\text { Normal but not } \\
\text { Alarmed } \\
\text { Conditions }\end{array}$ & $\begin{array}{l}\text { 1/TA, HSI } \\
\text { Design }\end{array}$ & $\begin{array}{l}\text { Operators failed to recognize and respond to } \\
\text { clearly off-normal conditions that were not } \\
\text { alarmed. This may be considered a failure in } \\
\text { situation awareness, and possibly involve } \\
\text { fixation on other situations. }\end{array}$ & $\begin{array}{l}\text { Outside } \\
\text { Source: } \\
\text { Nuclear } \\
\text { Industry } \\
\text { Issues } \\
\text { Identified in } \\
\text { NUREGs } \\
\end{array}$ & Active \\
\hline
\end{tabular}




\section{FUNCTIONAL REQUIREMENTS ANALYSIS AND FUNCTION ALLOCATION}

\subsection{Introduction}

An FRA/FA study was performed as part of the PPC and TCS modernization project at each of the utility's three plants. The study involved performing elements of the HFE program in support of designing and evaluating the HSIs for each plant's main control room (MCR). This chapter documents the results of the identification and analysis of PPC and TCS functions associated with the modernized PPCs and TCSs, and the initial allocation of functions to control room operators and automation. The second study element is TA, which is described in Chapter 4.

Relevant operator and control room functions for upgrades were identified using FRAs and FAs for all three plant MCRs as a part of a workshop. The first workshop involved control room operators from Plants A and B walking through challenging scenarios on the reconfigurable Human System Simulation Laboratory (HSSL) located at the INL (Boring et al., 2012 and 2013; see Figure 3). The HSSL provided glass-top simulator panels representing control boards located at the respective plants. The scenarios were developed prior to the workshop as part of the overall HFE study. Operators were briefed in advance of the scenario walk-throughs on possible capabilities of the modernized PPC and TCS, and provided demonstrations of advanced HSI developed concepts. They were asked during and following the scenario walk-throughs to identify new or changed functions and allocations that should be considered. Also, they were encouraged to identify additional changes that should be considered during modernization, e.g., provide related display information in one location to reduce moving between several panels to obtain the information.

Due to time constraints, the FRA/FA workshop for Plant $\mathrm{C}$ was conducted as part of the TA workshop at that plant's training simulator. The use of the training simulator did not afford the opportunity to demonstrate advanced HSI concepts as was possible at the HSSL.

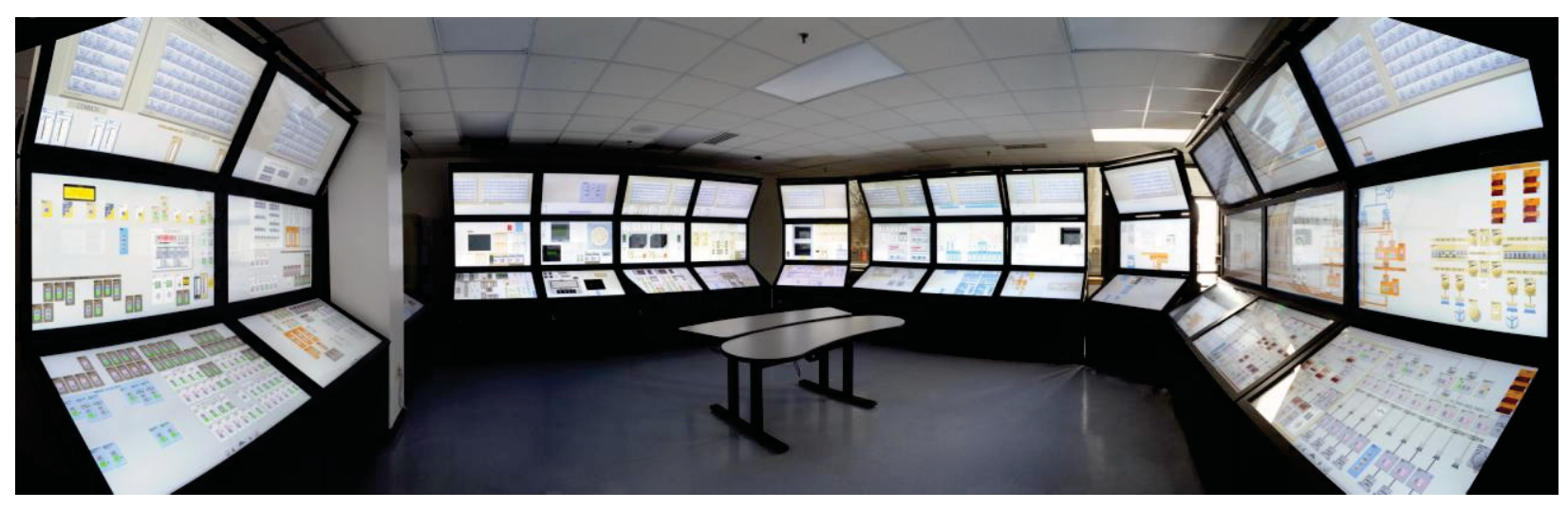

Figure 3. The Human System Simulation Laboratory at the Idaho National Laboratory. 


\subsection{FRA/FA Background}

As part of the systems engineering process, HFE activities for system upgrades as well as new designs focus on the role and function of humans as key elements in the industrial process. The human-centered analysis of systems and operations integrates the three elements of functional requirements, function allocation, and TA to establish design requirements for an HSI design, which, in nuclear power plants, forms part of the control room. The FRA/FA addresses operational aspects of the plant by systematically defining equipment, software, personnel and procedural data requirements that meet all functional objectives of the control room and its operating crew, including safe operation of the plant. It assists in determining the design of the plant and specific systems, particularly the control room HSI and its components required for safe plant shutdown. The various phases of this analysis collect parameters concerning the plant (and its various systems) and identify those required for the operating crew monitoring, cues for action, and feedback on actions taken. The analysis also identifies the main control and operating options available to operators for safe and economic plant operation. The plant processes that should be placed under operator control, and their relationships to each other, are also revealed.

\subsubsection{Definitions}

The following terms and definitions were applied in the FRA/FA workshop:

- Function: A function is defined as the operation(s) that must be performed by one or more systems in order to meet the mission goals of the plant. These functions may either be executed automatically by an automation system (AS), or initiated by the operator by means of the HSI, which in turn interfaces with the AS and the Distributed Control System (DCS) or systems like an Engineered Safety Feature Actuation System (ESFAS), Diverse Actuation System (DAS), Emergency Response Facility Information System (ERFIS) or Safety Parameter Display System (SPDS). Note that functions may refer to diagnosis activities such as gathering information and activation of controls. Thus, automation may pertain to consolidating relevant indicators into operator displays or to controlling the plant.

- Functional Requirements Analysis (FRA) Process: The FRA process typically consists of high- and low-level analysis phases required to define a system's functional architecture in terms of the operations that must be performed in order to meet the mission goals of the system.

In the high-level analysis, system functions are partitioned into requirements for sub-system functions. For a new system, no specific allocation is made yet to hardware, software, or humans. The allocation is based on the overall operational requirements and system mission. However, since the PPC is a known system with functions already well defined by both the vendor and user, the FRA part of the workshop focused only on identifying those functions that, due to the nature of operators' anticipated interaction with the system, might be targets for improvement.

In a low-level functional analysis, the aim is to decompose the high-level functions into a coherent set of executable functions associated with operational conditions or modes and specific systems and major components. The goal of the functional analysis at this level is to determine the functions that are associated with high-level operational goals and to create a framework for an understanding of the relative role of human, or system controllers. Again, due to the fact that the PPC is the de facto system chosen to present predetermined classes of information to the operator, only those functions identified in the high-level analysis are selected for further analysis. 
- Function Allocation (FA): FA is an analytical process that distributes defined functions between available resources (humans, hardware, software or combinations). The allocation of some functions will be mandatory and predetermined by constraints established during the requirements analysis phase. Allocation is also determined by comparison of performance between humans, hardware, software, cost factors, and cognitive support for operators. Allocation decisions are made to maximize total system performance and effectiveness, taking into consideration the contextual capabilities and limitations of systems and humans.

A rational allocation of functions to operators, hardware, or software is necessary for optimal system design. Function allocations provide the basis for subsequent efforts relating to crew or operator TA and description, operator performance analysis, display and control selection or design, and control room design, development, and evaluation. In particular, decisions on the allocation of functions affect operator workload and have a significant influence on staffing, selection, and training requirements.

It should be noted that FA does not propose any specific task or HSI requirements. Only during the TA process is it determined how the function allocation recommendations may affect or alter the performance of the operator or the system itself.

\subsubsection{Considerations for Function Allocation}

The allocation of functions to either machines or humans can be determined by a number of factors:

- Technology capability and limitations (i.e., technical feasibility)

- Human capability and limitations

- Operational requirements

- Nuclear safety requirements

- Equipment protection requirements

- Regulatory requirements

- Organizational requirements

- Cost, productivity and economic factors

All of these factors are normally considered already during the FRA to ensure that resources are applied in the most cost-effective manner.

Resulting from an assessment of these factors, each function allocation opportunity would be determined by the following criteria, based primarily on principles described in NUREG/CR-3331 (U.S. NRC, 1983):

- Need for alarm handling

- When large amounts of data must be stored

- Need for extensive data analysis or calculation

- Availability of proven technology

- Need for auto configuration

- When it is consistent with design practice

- When decision-making is too complex for humans (e.g. based on complex calculations)

- When events occur too rapidly for the human to respond

- When the operating crew prefers automation 
- When complex sequences must be controlled

- When it would be too costly for human operation.

The following are indications for potential human control of all or part of a process:

- When automation is not feasible or too costly

- When the system can provide adequate cognitive support

- When the process is not excessively difficult

- When human operation will provide job satisfaction

- When it is a regulatory or policy requirement

- When operators prefer to control the process and such control can be proven to be reliable.

When all the functions have been evaluated, there are often a number of tradeoffs to be made to motivate a decision for either automation, humans, or shared between the two, as for example depicted in Table 5. These tradeoffs need to be evaluated before the start of any system or HSI design activity.

Table 5. Cost Tradeoffs for Humans vs. Automation.

\begin{tabular}{|c|c|}
\hline Criterion & Description \\
\hline \multirow[t]{2}{*}{ Engineering trade-offs } & $\begin{array}{l}\text { Are there obvious improvements in engineering design that would reduce } \\
\text { human factors cost? }\end{array}$ \\
\hline & $\begin{array}{l}\text { Are there technology costs that could be reduced by allocation to the } \\
\text { operator? }\end{array}$ \\
\hline \multirow[t]{2}{*}{ Technical feasibility } & Can technology be developed in time? \\
\hline & Are costs acceptable? \\
\hline Technical consistency & Check for gross imbalance of technology between human and machine. \\
\hline \multirow[t]{2}{*}{ Balance of cost } & Have designers increased system cost by overemphasizing technology? \\
\hline & Have designers increased human cost by under-exploiting technology? \\
\hline Cost sustainability & $\begin{array}{l}\text { Can costs for both system and humans be sustained over the lifecycle of the } \\
\text { project? }\end{array}$ \\
\hline
\end{tabular}

\subsubsection{Objectives}

The objectives of this FRA and FA are to define new and changed PPC and TCS functions that must be carried out to satisfy plant safety and availability goals (FRA), and to assign responsibilities for those functions (FAs) to personnel and automation in a way that takes advantage of human and automation strengths and avoids human and automation limitations and weaknesses.

The FRA determines the objectives, performance requirements, and constraints of the HSI design, and sets a framework for understanding the role of personnel and automation in controlling PPC and TCS related plant processes. FA is the assignment of functions to personnel (manual control), automatic systems (automated control) and a combination of both (shared control). 
Taking advantage of functional capabilities provided by the modernized PPC and TCS, and allocating these functions appropriately between manual and automated controls and information displays will reduce human errors and inappropriate actions resulting in higher levels of system safety and economic performance.

\subsection{Methodology}

The HFE workshop methodology was based upon the principles described in the NUREG-0711 Revision 3 (O'Hara et al., 2012), EPRI Report 1010042 (2005) providing HFE guidance for control room design and modification, IEEE 1023 (2004) providing recommendations for applying HFE, and an EPRI HFE training course (2011). A graded approach was followed so only FRA/FA activities needed for this HFE study were performed (see definitions above, specifically for a high-level FRA). A major benefit of applying the graded approach is elimination of unnecessary work with assurance that all necessary HFE activities are complete.

A description of the workshops and simulator facility is presented in the sections that follow.

\subsection{Pre-Workshop Preparatory Activities}

\subsubsection{Analyses}

Analyses were performed to identify major functions that may change from current practices based on expected system changes introduced with the new PPC and TCS upgrades. Document sources reviewed and analyzed for the PPC upgrade included plant specific HSI specifications, system requirements, and HFE documents. Discussions with utility, plant, and other engineers involved in the modernization project provided additional information about changes expected with the upgrades.

\subsubsection{Planning Meeting}

A planning meeting was conducted with plant reactor operators, utility engineers, and the HFE members of the study team. The major planning meeting objectives were to:

- Identify significant events, scenarios and procedures impacted by the PPC and TCS upgrades in which functions and operator tasks will change

- Evaluate the large number of events, scenarios and procedures expected to be identified, and select the ones expected to have largest positive and negative impacts on operator and system performance

- Describe the events, scenarios and procedures in sufficient detail that they can be simulated during the FRA/FA workshop.

Criteria considered during the evaluation included those activities:

- Providing the greatest operator error traps and opportunities for human error and poor performance

- Offering the greatest opportunity for improved safety and economic performance

- Involving changes from manual to shared or automatic functions

- Involving the most changes in operator roles and responsibilities

- Involving increased operator workload and/or reduction in operator action times. 
Events, scenarios, and procedures identified during the planning meeting were further developed and refined prior to the FRA/FA workshop. Operators from the plants that participated in the planning meeting were responsible for finalizing the scenarios for their respective plants prior to the workshop.

\subsection{Workshop Overview}

\subsubsection{Initial Workshop}

The FRA/FA workshop was conducted in November 2012, at the HSSL in Idaho Falls, Idaho. Operators from Plants A and B performed the scenario walkthroughs separately. Plant A operators performed scenario walkthroughs first. One operator was at the simulator control boards, and a second operator served as procedure reader. A third person from the plant familiar with more advanced HSIs based on experience in non-nuclear plants observed and provided suggestions regarding technology capabilities. One Plant B operator performed scenario walkthroughs following completion of the Plant A sessions. Observers, including INL HF engineers, an HFE consultant, simulator experts from the INL, and an engineer from the utility recorded and later analyzed the functions and function allocations identified during the walkthroughs. The workshop participants are listed in Table 6.

Table 6. FRA/FA Workshop Participants.

\begin{tabular}{|ll|}
\hline Affiliation & Role \\
Independent Consultant: & Workshop Leader and Facilitator \\
Utility: & Reactor Operator (Plant A) \\
Utility: & Senior Reactor Operator, Procedure Reader (Plant A) \\
Utility: & Non-Licensed/Balance-of-Plant Operator (Plant A) \\
Utility: & Senior Reactor Operator, Procedure Reader (Plant B) \\
Utility: & Engineer, Observer \\
INL: & HFE Analyst \\
INL: & Simulator Scenario Coordinator \\
INL: & Engineer, Simulator Operator \\
INL: & Technical Support \\
\hline
\end{tabular}

At the end of the walkthroughs, an engineer demonstrated the design approach followed for advanced HSIs in European reactors. The purpose was to provide the reactor operators with other examples of HSIs than currently available in the plants' PPC and TCS prototypes. This was followed by a discussion of the technical and function allocation opportunities offered by different levels of automation and the effect that this might have on operator tasks and design requirements. The objective was to make them aware of alternative ways of information presentation and to stimulate creativity and own thinking in the early phase of this HFE project.

As previously noted, due to time constraints on the availability of operators, a standalone FRA/FA workshop was not conducted with Plant C. The FRA/FA part of the workshop was combined with the TA and formed part of a Licensed Operator Continuing Training session. Note, however that there were significant similarities between Plant A and Plant C, and information derived from the FRA/FA workshop with Plant A was generalized to Plant C. 


\subsection{NPP Scenarios and Walkthrough Results}

Separate scenarios involving use of ERFIS, SPDS, and PPC were generated for each plant and run through the HSSL glass-top simulator using reactor operators from the respective plants. Representative scenarios for one plant are provided in the tables below. Note that turbine-specific scenarios will be tested as part of a later phase, during the HSI design phase.

Table 7. Scenario 1: Rod Misalignment.

\begin{tabular}{|c|c|}
\hline $\begin{array}{l}\text { Scenario description and } \\
\text { purpose }\end{array}$ & $\begin{array}{l}\text { This scenario deals with a possible rod misalignment as indicated by axial flux } \\
\text { difference on the ERFIS display. } \\
\text { The main purpose of this scenario was to examine the safety function } \\
\text { performed by the systems involved in the scenario. This included the } \\
\text { ERFIS/SPDS, which does not perform a control function, but supports the } \\
\text { operator in identifying and diagnosing the condition. }\end{array}$ \\
\hline Primary PPC Function & Monitor the safety condition of the rod control system. \\
\hline Primary operator role & $\begin{array}{l}\text { Use ERFIS/SPDS displays to monitor and diagnose system condition and use } \\
\text { panel instruments and control board to perform corrective actions and } \\
\text { calculations (e.g. reactor power, rod position, rod withdrawal rate, matching } \\
\text { Tavg, Tref). }\end{array}$ \\
\hline $\begin{array}{l}\text { Simulator initial } \\
\text { conditions }\end{array}$ & $\begin{array}{l}\text { Plant at } 100 \% \text { power. An alarm is raised when a control rod drops into the } \\
\text { core. }\end{array}$ \\
\hline Operator response & $\begin{array}{l}\text { Procedure directed the operator to monitor power reduction, pressure levels } \\
\text { change, and reactor trip. The operator then observed the rod position and the } \\
\text { axial flux difference (AFD), volume control tank (VCT) and steam generator } \\
\text { volume displays on the ERFIS. Next actions were to reduce turbine load and } \\
\text { stabilize reactor cooling system (RCS) temperature. }\end{array}$ \\
\hline Observations & $\begin{array}{l}\text { During the scenario the simulator was stopped (frozen) at various steps and the } \\
\text { operator was asked to discuss how automation might help, if information or } \\
\text { functions might be combined, the availability of information needed to make } \\
\text { decisions, etc. } \\
\text { The indications involved in the scenario were distributed across the control } \\
\text { boards and the overriding impression during this scenario was the need for the } \\
\text { operator to move around a lot to find the information. In addition, the } \\
\text { information obtained from the SPDS/ERFIS is not integrated on the control } \\
\text { boards (e.g., the ERFIS control rods displays are at the back of the control } \\
\text { room), which makes it possible to miss something if the rod misalignment } \\
\text { were to occur during a power maneuver. }\end{array}$ \\
\hline $\begin{array}{l}\text { Preliminary function } \\
\text { allocation findings }\end{array}$ & $\begin{array}{l}\text { Automation of some low level functions and trend displays of critical } \\
\text { information would avoid potential errors and reduce the time required for the } \\
\text { BOP operator to do field inspections (e.g., matching Tavg and Tref } \\
\text { temperatures by automating turbine control; providing context-sensitive } \\
\text { menus and information on PPC based on alarm states). }\end{array}$ \\
\hline Summary & $\begin{array}{l}\text { Where functions are automated, it is vital that the mode of operation be visible } \\
\text { to the operator at all times. Safety critical functions that need to happen } \\
\text { immediately should be automated, but those functions related to stabilizing the } \\
\text { plant require operator decision-making and should not be automated. Some } \\
\text { plant modes lend themselves better to automation, depending on the dynamics } \\
\text { of the plant. Highly dynamic plant modes risk operator losing situational } \\
\text { overview, if too much automation is incorporated. }\end{array}$ \\
\hline
\end{tabular}

Table 8. Scenario 2: Containment of Unidentified Leak. 


\begin{tabular}{|c|c|}
\hline $\begin{array}{l}\text { Scenario description and } \\
\text { purpose }\end{array}$ & $\begin{array}{l}\text { Detect and mitigate small leaks that would not show up as leaks elsewhere. } \\
\text { This includes obtaining information necessary to perform leak rate } \\
\text { calculations. Once a leak is detected, procedure AOP-016 directs the operator } \\
\text { to determine the source of the leak and correct it. }\end{array}$ \\
\hline Primary PPC Function & Monitor the safety condition of the RCS and related support systems \\
\hline Primary operator role & $\begin{array}{l}\text { Use ERFIS/SPDS displays in conjunction with panel instruments to obtain } \\
\text { information necessary to detect a small leak and restore plant to a stable } \\
\text { condition. Perform lookups and calculations (e.g., leak location, leak rate). } \\
\text { Use control board to perform corrective actions. }\end{array}$ \\
\hline $\begin{array}{l}\text { Simulator initial } \\
\text { conditions }\end{array}$ & $\begin{array}{l}\text { Plant at } 100 \% \text { power, followed by leak in chemical volume control } 25 \mathrm{E} \text { at } 60 \\
\text { gallon per minute (gpm). }\end{array}$ \\
\hline Operator response & $\begin{array}{l}\text { In this scenario, the operator first notices a change in VCT level while } \\
\text { monitoring the boards. The change in level suggests that RCS water is being } \\
\text { lost somewhere. This requires the operator to check several indications. These } \\
\text { checks included the volume of RCS leakage, makeup capability of the RCS } \\
\text { and radiation indications. Some of these indications are on the ERFIS as well, } \\
\text { but it takes a while to retrieve this information. }\end{array}$ \\
\hline Observations & $\begin{array}{l}\text { A key observation was that the operator needed to keep several items in } \\
\text { memory while searching for information. This includes the relevant and } \\
\text { related procedures, the relationship between the various indications, } \\
\text { performing calculations of leak rates, and the need to respond within } 15 \\
\text { minutes in the event of a radioactive release. Leak rate calculations for rates } \\
\text { more than } 25 \text { gpm are currently performed on an Excel spreadsheet on a } \\
\text { desktop computer. }\end{array}$ \\
\hline $\begin{array}{l}\text { Preliminary function } \\
\text { allocation findings }\end{array}$ & $\begin{array}{l}\text { Much of the process of seeking information could be automated by having } \\
\text { displays calibrated to specific procedures and automatically displaying the } \\
\text { information required to step through each procedure. }\end{array}$ \\
\hline Summary & $\begin{array}{l}\text { The need for information accessibility suggested a need for integration of } \\
\text { pertinent information on the control boards. Ultimately this could lead to the } \\
\text { simplification of procedures in a way that would simplify decision-making. } \\
\text { Operators also discussed the need for a display of trends of key information } \\
\text { currently available on the PPC, and also for the integration of back panel } \\
\text { indications that are not visible in the control room, e.g., drywell leakage sump } \\
\text { values. } \\
\text { Operators indicated that having diverse indicators collected on relevant } \\
\text { displays could help diagnosis and response. }\end{array}$ \\
\hline
\end{tabular}


Table 9. Scenario 3: Double-Ended Break on Cold Leg.

\begin{tabular}{|c|c|}
\hline $\begin{array}{l}\text { Scenario description and } \\
\text { purpose }\end{array}$ & $\begin{array}{l}\text { This scenario involved a double-ended break, leading to a loss of cooling } \\
\text { accident (LOCA), primary to secondary leak, with no safety injection. } \\
\text { This scenario had many alarms, added time pressure and many indications to } \\
\text { check. This required an extensive procedure to calculate leak rate, isolate the } \\
\text { leak and reset the plant to a stable condition. }\end{array}$ \\
\hline Primary PPC Function & $\begin{array}{l}\text { Monitor the safety condition of the RCS, steam generator (SG), turbine and } \\
\text { related support systems }\end{array}$ \\
\hline Primary operator role & $\begin{array}{l}\text { Use ERFIS/SPDS displays in conjunction with panel instruments to identify } \\
\text { and diagnose the large break (e.g., leak location, leak rate) and restore the } \\
\text { plant to a stable condition. Use control board to perform corrective actions. }\end{array}$ \\
\hline $\begin{array}{l}\text { Simulator initial } \\
\text { conditions }\end{array}$ & $\begin{array}{l}\text { Plant at } 100 \% \text { power. Fault chemical volume control system } 05 \mathrm{~A} \text { at a leak rate } \\
\text { of } 458 \mathrm{gpm} \text {. }\end{array}$ \\
\hline Operator response & $\begin{array}{l}\text { The first response required of the operator was to isolate the letdown path. The } \\
\text { operator had to rely on redundant and diverse indications, i.e., from the control } \\
\text { boards and from the ERFIS/SPDS. This included identification of abnormal } \\
\text { component functions associated with loss of inventory. For the diagnosis of } \\
\text { the cause the operator relied mostly on the ERFIS screens, but had to decide } \\
\text { what was out of range. }\end{array}$ \\
\hline Observations & $\begin{array}{l}\text { A significant amount of complex diagnosis is involved with the accompanying } \\
\text { potential of human error, which could lead to equipment damage, a } \\
\text { radiological incident, or both. The complexity of the scenario was exacerbated } \\
\text { by a pump trip, which eventually led to a reactor trip. This required a } \\
\text { transition into emergency operating procedures and immediate actions, e.g., } \\
\text { verification of automatic functions such as reactor trip and turbine trip. }\end{array}$ \\
\hline $\begin{array}{l}\text { Preliminary function } \\
\text { allocation findings }\end{array}$ & $\begin{array}{l}\text { As with Scenario 1, ERFIS displays should be linked to specific procedures } \\
\text { and automatically display the information required to step through each } \\
\text { procedure. Information should be processed to provide appropriate time lines } \\
\text { and trends. This would include automatic collation and display of plant state } \\
\text { information. }\end{array}$ \\
\hline Summary & $\begin{array}{l}\text { This intense scenario was characterized by significant workload and time } \\
\text { pressure. This was caused primarily by the amount of information required } \\
\text { from diverse sources, time pressure, and complexity of diagnosis and decision- } \\
\text { making required by the procedure. } \\
\text { It was apparent that the task could be simplified significantly and error } \\
\text { potential reduced by allocating specific functions to the system. Discussion } \\
\text { with operators revealed the following system requirements: } \\
\text { ERFIS/SPDS information should be grouped to make verification easier. The } \\
\text { procedure requires making a four-way distinction of possible faults. More } \\
\text { pertinent information is required to simplify decision-making. } \\
\text { Since several timelines including continuous actions are involved in a scenario } \\
\text { like this, it is very difficult for the operator to keep track of the evolution of } \\
\text { specific conditions. }\end{array}$ \\
\hline
\end{tabular}


Table 10. Scenario 4: Small Steam Generator Leak.

\begin{tabular}{|c|c|}
\hline $\begin{array}{l}\text { Scenario description and } \\
\text { purpose }\end{array}$ & $\begin{array}{l}\text { This scenario involved the diagnosis of a small leak, following detection of an } \\
\text { indication on the Radiation Monitoring System (RMS). Precise indications are } \\
\text { needed for very small leaks and the operator had curves indicated by the SPDS } \\
\text { to calculate the leak rate. The scenario ended when the procedure reached } \\
\text { Start Normal Shutdown. }\end{array}$ \\
\hline Primary PPC Function & $\begin{array}{l}\text { Monitor the safety condition of the RCS, SG, turbine and related support } \\
\text { systems. }\end{array}$ \\
\hline Primary operator role & $\begin{array}{l}\text { Use ERFIS/SPDS displays to identify and diagnose the SG leak and restore } \\
\text { the plant to a stable condition. }\end{array}$ \\
\hline $\begin{array}{l}\text { Simulator initial } \\
\text { conditions }\end{array}$ & Plant at $100 \%$ power. Insert steam generator tube rupture $07 \mathrm{~A}$ at $1 \mathrm{gpm}$. \\
\hline Operator response & $\begin{array}{l}\text { Upon finding an indication of RCS leakage in the VCT, the operator checked } \\
\text { that alarms were clear and assessed the need for evacuation. After ordering the } \\
\text { evacuation as required by the procedure, the operator proceeded to evaluate } \\
\text { the technical specifications for the leakage. } \\
\text { The diagnosis method required the operator to convert the Rad monitor } \\
\text { indications to gallons per day (Steps } 14-19 \text { in procedure). This was a time } \\
\text { consuming process that removes the operator from other tasks. It was } \\
\text { determined that this leak rate calculation could be automated, assuming } \\
\text { suitable sensors and instrumentation were available. This would avoid the } \\
\text { need to look up the curve and perform the calculations. }\end{array}$ \\
\hline Observations & $\begin{array}{l}\text { Similar to Scenario } 3 \text {, complex diagnosis was required, based on many } \\
\text { indications. The complexity of the scenario was exacerbated by a pump trip, } \\
\text { which eventually led to a reactor trip. This required a transition into } \\
\text { emergency operating procedure and immediate actions, such as verification of } \\
\text { automatic functions including reactor trip and turbine trip. The scenario was } \\
\text { characterized by the potential for human error, which could lead to equipment } \\
\text { damage, a radiological incident, or both. }\end{array}$ \\
\hline $\begin{array}{l}\text { Preliminary function } \\
\text { allocation findings }\end{array}$ & $\begin{array}{l}\text { Leak rate calculations from the radiation monitor should be assigned to the } \\
\text { PPC. This includes providing the results in an easily accessible form. }\end{array}$ \\
\hline Summary & $\begin{array}{l}\text { As with the previous scenario, a serious leak would require transition to the } \\
\text { emergency operating procedure for steam generator tube rupture, possible } \\
\text { evacuation of the RAB and Turbine Building, and again the need to be aware } \\
\text { of different time lines was observed. }\end{array}$ \\
\hline
\end{tabular}




\subsection{Functional Requirements Analysis Summary}

Table 11 provides a brief summary of representative functions identified from the workshop with Plant A. Similar summaries were produced for Plants B and C.

Table 11. PPC Function Summary.

\begin{tabular}{|c|l|l|}
\hline Scenario & System Function & Operator Role \\
\hline 1 & $\begin{array}{l}\text { Monitor the safety condition of the } \\
\text { rod control system }\end{array}$ & $\begin{array}{l}\text { Use ERFIS/SPDS displays to monitor and diagnose } \\
\text { system condition and use panel instruments and } \\
\text { control board to perform corrective actions and } \\
\text { calculations (e.g., reactor power, rod position, rod } \\
\text { withdrawal rate, matching Tavg, Tref) }\end{array}$ \\
\hline 2 & $\begin{array}{l}\text { Monitor the safety condition of the } \\
\text { RCS and related support systems }\end{array}$ & $\begin{array}{l}\text { Use ERFIS/SPDS displays in conjunction with panel } \\
\text { instruments to obtain information necessary to detect a } \\
\text { small leak and restore plant to a stable condition. } \\
\text { Perform lookups and calculations (e.g., leak location, } \\
\text { leak rate). Use control board to perform corrective } \\
\text { actions. }\end{array}$ \\
\hline 3 & $\begin{array}{l}\text { Monitor the safety condition of the } \\
\text { RCS, SG and related support } \\
\text { systems during a double-ended break }\end{array}$ & $\begin{array}{l}\text { Use ERFIS/SPDS displays in conjunction with panel } \\
\text { instruments to identify and diagnose the primary to } \\
\text { secondary leak (e.g., leak location, leak rate) and } \\
\text { restore the plant to a stable condition. Use control } \\
\text { board to perform corrective actions. }\end{array}$ \\
\hline 4 & $\begin{array}{l}\text { Monitor the safety condition of the } \\
\text { RCS, SG, turbine and related support } \\
\text { systems. }\end{array}$ & $\begin{array}{l}\text { Use ERFIS/SPDS displays in conjunction with panel } \\
\text { instruments to identify and diagnose the SG leak and } \\
\text { restore the plant to a stable condition. }\end{array}$ \\
\hline
\end{tabular}

\subsection{Function Allocation Summary}

Based on the functions and operator roles described above, Table 12 identifies high-level function allocation opportunities for Plant A. Across all three plants, several of these allocations and decision criteria are similar or redundant.

\subsection{Conclusions}

The FRA/FA workshop served a dual purpose:

- The main objective of the functional requirements analysis was to identify the PPC and associated TCS functions that must be carried out to satisfy plant safety and availability goals.

- The objective of the function allocation analysis was to determine the technical and human factors basis for assigning responsibilities for those identified functions to personnel and automation in a way that avoids the limitations and exploits the capability of humans and automation. 
Table 12. PPC Function Allocations.

\begin{tabular}{|c|l|l|l|}
\hline Scenario & System Function & Allocation description & Criteria \\
\hline 1 & $\begin{array}{l}\text { Monitor the safety } \\
\text { condition of the rod } \\
\text { control system }\end{array}$ & $\begin{array}{l}\text { Automate low level functions and } \\
\text { trend displays of critical } \\
\text { information (e.g., matching Tavg, } \\
\text { Tref temperatures). } \\
\text { Automate turbine control } \\
\text { Provide context-sensitive menus } \\
\text { and information on PPC based on } \\
\text { alarm states. }\end{array}$ & $\begin{array}{l}\text { Avoid potential errors and } \\
\text { reduce the time required for } \\
\text { the BOP operator to do field } \\
\text { inspections }\end{array}$ \\
\hline 2 & $\begin{array}{l}\text { Monitor the safety } \\
\text { condition of the RCS } \\
\text { and related support } \\
\text { systems }\end{array}$ & $\begin{array}{l}\text { Calibrate displays to specific } \\
\text { procedures and automatically } \\
\text { display the information required to } \\
\text { step through each procedure. }\end{array}$ & $\begin{array}{l}\text { Time required to collect } \\
\text { information from diverse } \\
\text { sources }\end{array}$ \\
\hline 3 & $\begin{array}{l}\text { Monitor the safety } \\
\text { condition of the RCS, } \\
\text { SG, turbine and related } \\
\text { support systems }\end{array}$ & $\begin{array}{l}\text { As with Scenario 2: Link ERFIS } \\
\text { displays to specific procedures and } \\
\text { automatically display the } \\
\text { information required to step } \\
\text { through each procedure. } \\
\text { Process information to provide } \\
\text { appropriate time lines and trends. } \\
\text { This includes automatic collation } \\
\text { and display of plant state } \\
\text { information. } \\
\text { Group ERFIS/SPDS information }\end{array}$ & $\begin{array}{l}\text { Reduce clutter of displays } \\
\text { Simplification of procedures } \\
\text { (four-way distinction of } \\
\text { faults) } \\
\text { Simplification of } \\
\text { information verification }\end{array}$ \\
\hline 4 & $\begin{array}{l}\text { Monitor the safety } \\
\text { condition of the RCS, } \\
\text { SG, turbine and related } \\
\text { support systems. }\end{array}$ & $\begin{array}{l}\text { Assign leak rate calculations from } \\
\text { the Rad monitor to the PPC. } \\
\text { Provide results in an easily } \\
\text { accessible form. }\end{array}$ & $\begin{array}{l}\text { Simplify information access } \\
\text { Error prevention }\end{array}$ \\
\hline
\end{tabular}

Functions associated with the PPC upgrade were identified and function allocations for the scenarios were evaluated during the workshop. The step-by-step method followed in the scenario walkthroughs helped to identify the functions and requirements associated with the planned PPC upgrade. Although some simulator limitations prevented more detailed identification of the implications of displays embedded on the control room panels, this did not detract significantly from achieving the workshop objectives, that is, identifying key functions of the target system and opportunities for refining the allocation of those functions to either operator or system.

In addition to the identification and analysis of functions and the relative roles of humans and systems, the workshop also helped to create a better understanding of needs associated with the planned system and control room upgrades. Participants discussed the impact of the upgrades on the ways functions are allocated and the resulting information needs, the effect on how procedures are conducted, and the effect on operator performance, especially response times, reduction of workload, and reduction of human error potential. The advanced HSI prototype presented in the HSSL in particular helped to make participants aware of the potential of advanced technologies and visualization methods available to simplify the operator's task and reduce error potential. 
During the reviews of the identified functions and opportunities for improvement at the end of the workshop, the general conclusions were as follows:

- The identified functions were valid for the target system

- Potential function allocation changes would be reviewed during the TA phase

- A desired end state would be to provide operators with more salient information for specific operational conditions and to integrate such information into the operator's immediate workspace, which would contribute to improved operator performance.

The availability of such information would require assigning specific functions to the PPC, which would achieve the following ideals:

- Reduce the need to move around the control room to obtain information from spatially diverse sources

- Reduce the need for the operator to keep a lot of information in short-term memory

- Reduce the need to retrieve a lot of information from long-term memory

- Reduce or eliminate the need for mental or handwritten calculations for accurate diagnoses

- Simplify the mental integration of information.

This chapter also briefly describes how preliminary function allocation recommendations would be translated into operator performance requirements and subsequently into HSI design requirements. It must be emphasized that initial assumptions about the desired end state and the potential benefits of allocations described above are not meant to be design requirements. As described in Section 3.2.2 (Considerations for Function Allocation), these initial concepts are subject to more detailed analysis of the trade-offs during and after TA.

\subsection{Recommendations}

Based on the conclusions above, the following recommendations are made for the implementation of the results of a FRA/FA in TA workshops.

- The suitability and validity of scenarios employed during an FRA/FA workshop should be confirmed for use during the TA workshops. Where additional scenarios are identified during a FRA/FA workshop, those scenarios should be described accurately and included with the scenarios tested during the TA workshop for the particular plant. In particular, it is recommended that scenario descriptions should follow a standard format, similar to those used for licensed operator training sessions.

- The functions identified and function allocations made during the FRA/FA workshop should be reviewed in preparation for TA workshops and the required fidelity of the simulations should be determined.

- Where modernization of specific systems is envisioned, operators should be briefed on the potential features of advanced HSIs, such as those presented as advanced HSIs in the HSSL, prior to their participating in walkthroughs or discussions of desirable features with the modernized equipment. This will help them to think "outside the box."

- The implementation of enhancements of the HSSL simulator makes it more suitable for support of future PPC and TCS modernization projects. It would serve as a tool to evaluate HSI design options and operator interaction with such enhancements. 


\section{TASK ANALYSIS}

\subsection{Scenario Observations}

\subsubsection{Introduction}

Three separate TA workshops were conducted at the training simulators for Plants A, B, and C in December 2012, February 2013, and April 2013, respectively. The objectives of the workshop were to identify and describe tasks associated with the PPC upgrade planned for all three plants. Consideration was given to functions and function allocations identified during the FRA/FA Workshop conducted at the INL in November 2012. Particular attention was paid to potential improvements in tasks and procedures offered by technical capabilities provided by the new PPC and TCS. To this end, the TA focused on identifying information and performance requirements that could lead to the implementation of previously identified function allocations in the subsequent HSI design phase.

The TA was performed as part of the Conceptual Design phase for the PPC and TCS upgrade, and was limited to considering those scenarios judged by the HFE team as being most challenging for the modernization planned. It is expected that more task analyses may be performed during preliminary design when the PPC and TCS technical designs are nearing completion and functions and operator tasks can be reassessed based on the then current modernization design.

\subsubsection{Purpose}

The purpose of the TA workshops was to identify and analyze the specific tasks that need to be performed by operators to accomplish the requirements of specific as well as general operational conditions. TA defines the information, control, and human performance requirements for various operational scenarios. The ultimate aim of the TA phase of control room modernization is to develop high-level sequential descriptions of the operations that must be carried out to fulfill the functions of a particular system.

In this project a task is defined as a group of related activities with a common objective, often occurring in close temporal proximity. The results of TA serve as inputs to subsequent HFE elements and activities described in NUREG-0711, Revision 3 (O'Hara et al., 2012), such as HSI design, procedures development, training program development, verification and validation, staffing and qualifications, and job design.

\subsubsection{Method and Scope}

As indicated previously, the aim of TA is to develop a high-level sequential description of the operations that must be carried out to fulfill the functions of a particular system in terms of operational sequences. The narrative description, developed during the functional analysis stage, establishes the foundation for the sequential descriptions. Because of the close relationship and interdependence between functions and tasks, it is possible under special circumstances to combine three key methods that are often performed separately: FRA, FA, and TA. The combined approach focuses on the human and system performance requirements that must be met to fulfill the functions of the system.

The main objective of the FRA/FA part of the project was to identify the PPC and associated TCS functions that must be carried out to satisfy plant safety and availability goals. Special attention was paid to the technical and human factors requirements for reassigning responsibilities for the identified 
functions to personnel and automation in a way that avoids the limitations and exploits the capabilities of humans as well as automation.

The conversion of functions into tasks consists of developing a sequential description of the operations identified in the FRA. These sequential descriptions of operations for a specific function are based upon an analysis of the interactions between human and system entities and are best performed using a modified Operational Sequence Analysis methodology. The sequences of human and system actions needed for each process are called Operating Sequences. These, in turn, can be broken down into tasks, sub-tasks, and task elements. Such a breakdown has the following advantages:

- Since the human and system actions are defined at a high functional level, they are often repeated in other operating sequences, thereby reducing the number of analyses.

- Each Operating Sequence can independently focus on detail of its tasks and subtasks by keeping the description of the other processing elements at a high level. (Note: the identification of human dependencies in risk important accident sequences is addressed in probabilistic risk analysis and human reliability analysis [PRA/HRA] and does not form part of this method).

Given that the operation of a system forms part of the overall operation of the plant, it is necessary to define the conditions under which the operating sequence under study is carried out. In order to develop the descriptions of the operating sequences, it is necessary to define scenarios that include all the operations that can be performed with the system. This must be done in such a way that all the possible alignments and modes of change in normal, abnormal, and emergency conditions appear. These scenarios minimally contain the following:

- Initial Conditions

- Sequence Initiator

- Final Condition

- Operation Classification (i.e. Normal and Abnormal Operation)

- Progression of Action. This comprises the operating sequence descriptions developed from each scenario and will contain at least the following:

- Phases and maneuvers.

- An indication of the relationships among actions within a sequence.

- How those actions are coordinated and how pertinent information is transferred.

The criteria for the selection of scenarios and operating sequences are based on the following:

- Function of the system that is being studied (as defined in the systems design description)

- Operating modes and change modes of the system

- Plant operating modes

- Operating procedures of the plants

- Maintenance operations necessary for system functioning

- Likelihood of system/component failure

- Operating experience.

The narrative descriptions of functions created during the FRA/FA stage thus established the foundation for task descriptions. The systematic translation of those functions into tasks first required observation of the actual tasks as they were being performed. Next, those tasks were examined again during development of a sequential description of the operations identified in the FRA. The TA therefore used the same scenarios as for the FRA/FA for Plants A and B. The TA procedure for Plant $\mathrm{C}$ had to be 
adapted to fit in with the scheduled operator training session. In the case of Plant $\mathrm{C}$, a combined FRA, FA, and TA workshop was held. Since Plant C is similar to Plant A, the initial findings from Plant A helped streamline the process for Plant C.

A four-step process was followed to observe and document information obtained during the scenario walkthroughs:

\section{Step 1: Observation of operator actions during scenarios}

This part of the process consisted of one or more analysts quietly observing and recording operator activity. This method made use of computer-based forms that allowed the capture of start and end times of significant actions or events during the first scenario trials. Specific attention was paid to actions or functions that could be improved or simplified by allocation to automation or by providing task support. This method minimized the intrusion operators may otherwise experience from too frequent interrogation by the analyst. A typical shortcoming of this method was the difficulty in recording sufficient detail of the activity. This was mitigated through the other three steps, described below, which helped to produce a detailed analysis.

Some scenarios received multiple walkthroughs, the first walkthrough to allow the operators to proceed through the event naturally without interruption by the observers, and a second time with a think-aloud method in which the operators explained their decisions and actions, frequently with intentional simulator runtime pauses to allow questions from the observers.

\section{Step 2: Debrief and summary discussions}

This consisted of a group review of the scenarios whereby the primary focus was on those actions or events that could indicate opportunities for improved task and HSI design, due to workload, error probability, or some other inefficiency.

\section{Step 3: Identification of operator performance requirements}

This part of the analysis was conducted as part of the debriefing sessions and focused on identifying some cognitive and physical performance requirements for the task. The analyst used pre-prepared forms (see Table 13 for an example) to record additional information that also helped participants to understand how task performance is influenced by the procedures and by the current design of the system and control boards.

The following dimensions of performance were analyzed:

- Information requirements (alarms, alerts, values, instructions)

- Decision-making requirements (decision type, evaluation type)

- Response requirements (frequency, error tolerance, concurrent tasks, accuracy, consequences of incorrect or non-performance, time constraints)

- Communication requirements (written, verbal)

- Workload factors (visual, auditory, cognitive, physical)

- Task support requirements (procedures, job aids). 
Table 13. Scenario 1 Task Performance Requirements.

\begin{tabular}{|c|c|}
\hline Task Performance Category & Description \\
\hline \multicolumn{2}{|l|}{ Information Requirements } \\
\hline Alarms and alerts & Rod control system alarm \\
\hline Performance parameters & Time when rod dropped, Tref, Tavg, Turbine load, boron concentration \\
\hline Feedback needed & Time lapse indication \\
\hline \multicolumn{2}{|l|}{ Decision-making requirements } \\
\hline Decision type & Calculate, compare, check, table lookup \\
\hline Evaluation to be performed & Reactor power, boron concentration, EOL matrix, blown fuses \\
\hline Decision for approval & Reactor at or above $10 \%$ \\
\hline \multicolumn{2}{|l|}{ Response requirements } \\
\hline Task Criticality Rating & Medium \\
\hline Type of action & Monitoring, control, recovery \\
\hline Concurrent tasks & Continuous monitoring, rechecking \\
\hline Task frequency & Monitoring throughout scenario \\
\hline Task tolerance & Incorrect control could lead to damage or reactor trip \\
\hline Task accuracy & Accurate identification of situation, accurate reading of DPRI indication \\
\hline Consequence of incorrect performance & Incorrect control could lead to damage or reactor trip \\
\hline Time constraints & Moderate time constraint - condition could lead to tech spec violation \\
\hline Time required & Not specified \\
\hline Physical position & Mainly at primary controls \\
\hline \multicolumn{2}{|l|}{ Communication requirements } \\
\hline Communications for monitoring & 3-way communication between RO \& SRO \\
\hline Communications with BOP & Possible communication with Reactor Engineering \\
\hline \multicolumn{2}{|l|}{ Workload factors } \\
\hline Visual & High \\
\hline Auditory & High \\
\hline Cognitive & High \\
\hline Psychomotor & Low \\
\hline Channel overlap & All \\
\hline \multicolumn{2}{|l|}{ Task support requirements } \\
\hline Protective clothing & N/A \\
\hline Job aids & N/A - "Shot clocks" or time lapse task timers are desirable \\
\hline Tools and equipment & N/A \\
\hline \multicolumn{2}{|l|}{ Workplace factors } \\
\hline Site ingress/egress paths & N/A \\
\hline Workspace envelope & Control Room \\
\hline Environmental conditions & Normal \\
\hline \multicolumn{2}{|l|}{ Performance Shaping Factors } \\
\hline Stress & Moderate \\
\hline Staffing (reduced or excess) & Normal CR crew \\
\hline Fatigue & Low \\
\hline Hazards involved & None \\
\hline
\end{tabular}

\section{Step 4: Operational Sequence Analysis}

The sequential description of tasks related to the functions identified during FRA/FA and observed during the simulator walkthroughs required a systematic analysis of the interactions between operators and systems during the operational scenarios listed before.

An Operational Sequence Analysis (OSA) was conducted collaboratively between analysts and operators at the end of the day's walkthroughs. The scenarios were reviewed, and a software program was used to interactively record the information in operational sequence diagrams (OSDs). The method adopted here consisted of identifying the key human and system "actors" in the scenarios, the interactions between them, and the information (signals) produced by systems that were accessed by operators. It was possible 
in each operating sequence to independently focus on details of tasks and subtasks by keeping the description of the other processing elements (i.e., system functions) at a high level. The sequential actions were plotted on a timeline that also helped to decompose functions into tasks, sub-tasks, and task elements.

Figure 4 contains the OSD for Scenario 1 discussed in the previous chapter and run again for the TA workshop. The OSD for the scenario contains the following information:

- Initial Conditions and system states

- Sequence Initiator (i.e., the "trigger" - usually an alarm)

- Information passed between entities (e.g., signal data or control commands)

- Final Condition (i.e., the end state)

- Progression of Action (this comprises the operating sequence descriptions developed from each scenario and typically contains the major actions or events and maneuvers, an indication of the relationships among actions within a sequence, and how those actions are coordinated and how pertinent information is transferred between entities).

The graphical notation for the OSD is explained in Table 14.

Table 14. Graphical Conventions Used in Operational Sequence Diagrams.

\begin{tabular}{|c|c|c|}
\hline Name, Description & Symbol & Meaning \\
\hline Human Actor & 우 & Any person involved in the scenario \\
\hline Arrow & $\longleftarrow$ & Information/data flow or command \\
\hline Rectangle & Action & Action \\
\hline Rounded rectangle & State & System State \\
\hline In-line text & Inline Text & Explanatory note \\
\hline $\begin{array}{l}\text { Long shaded bar spanning } \\
\text { time lines }\end{array}$ & & Steady State \\
\hline $\begin{array}{l}\text { Double line with braces } \\
\text { spanning time lines }\end{array}$ & & Scenario Start, Scenario end \\
\hline Braces & 2 & Start and end of series of actions \\
\hline Timer & $\underline{\nabla}$ & Timer Start \\
\hline Timer & $\rightleftarrows$ & Timer End \\
\hline
\end{tabular}


Figure 4. Scenario 1 Operational Sequence Diagram.

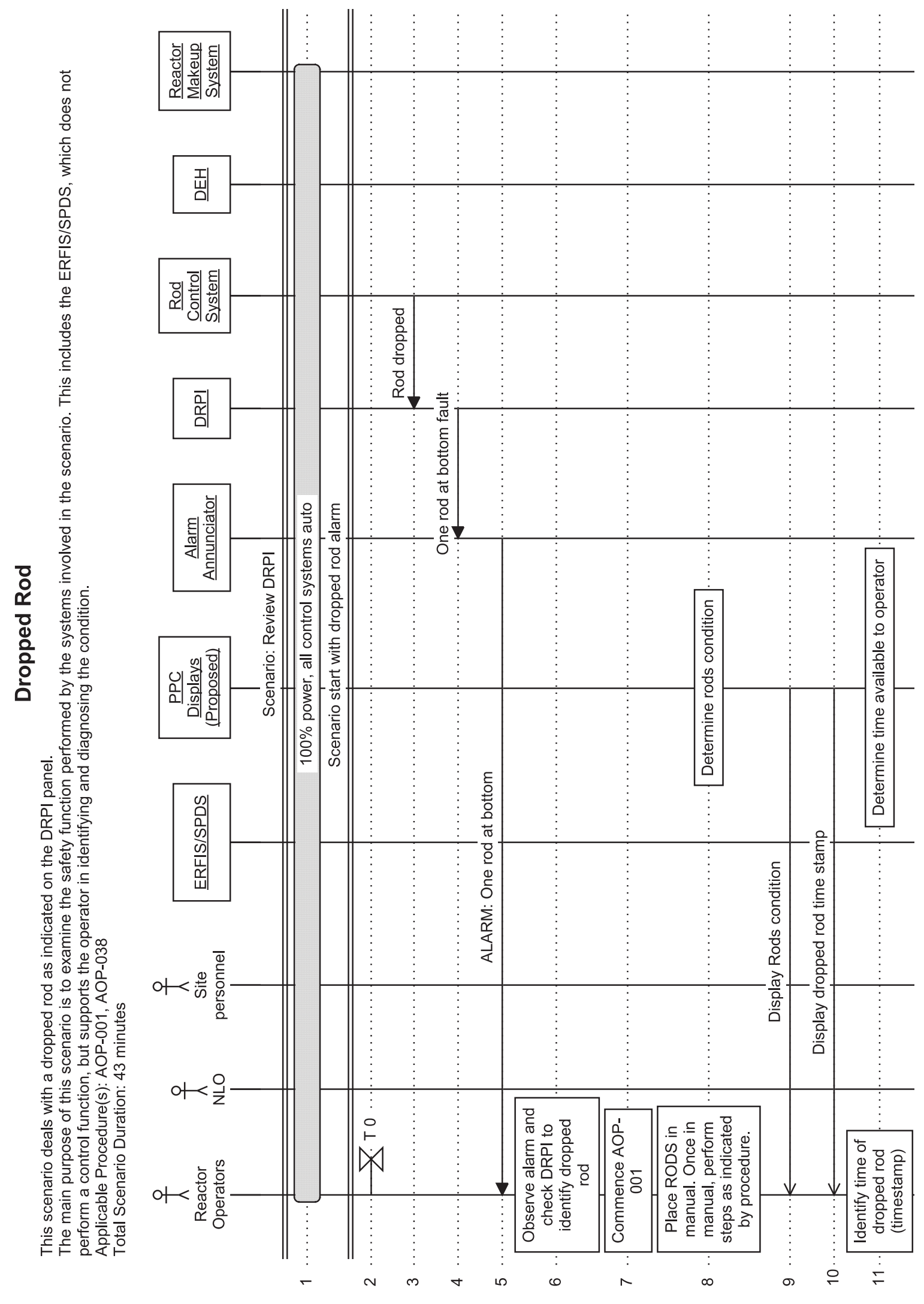


Figure 4. Scenario 1 Operational Sequence Diagram. (Continued)

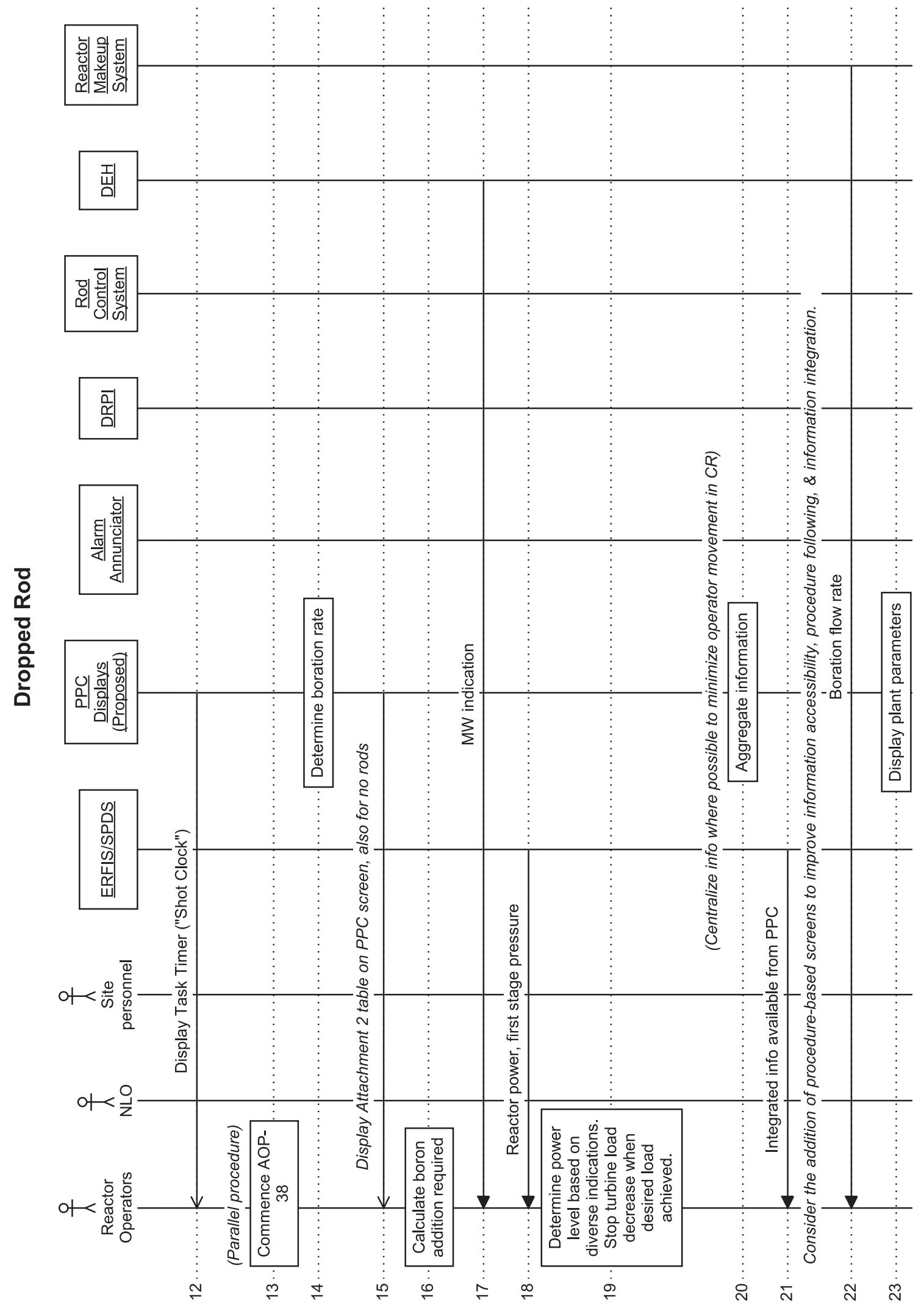


Figure 4. Scenario 1 Operational Sequence Diagram. (Continued)

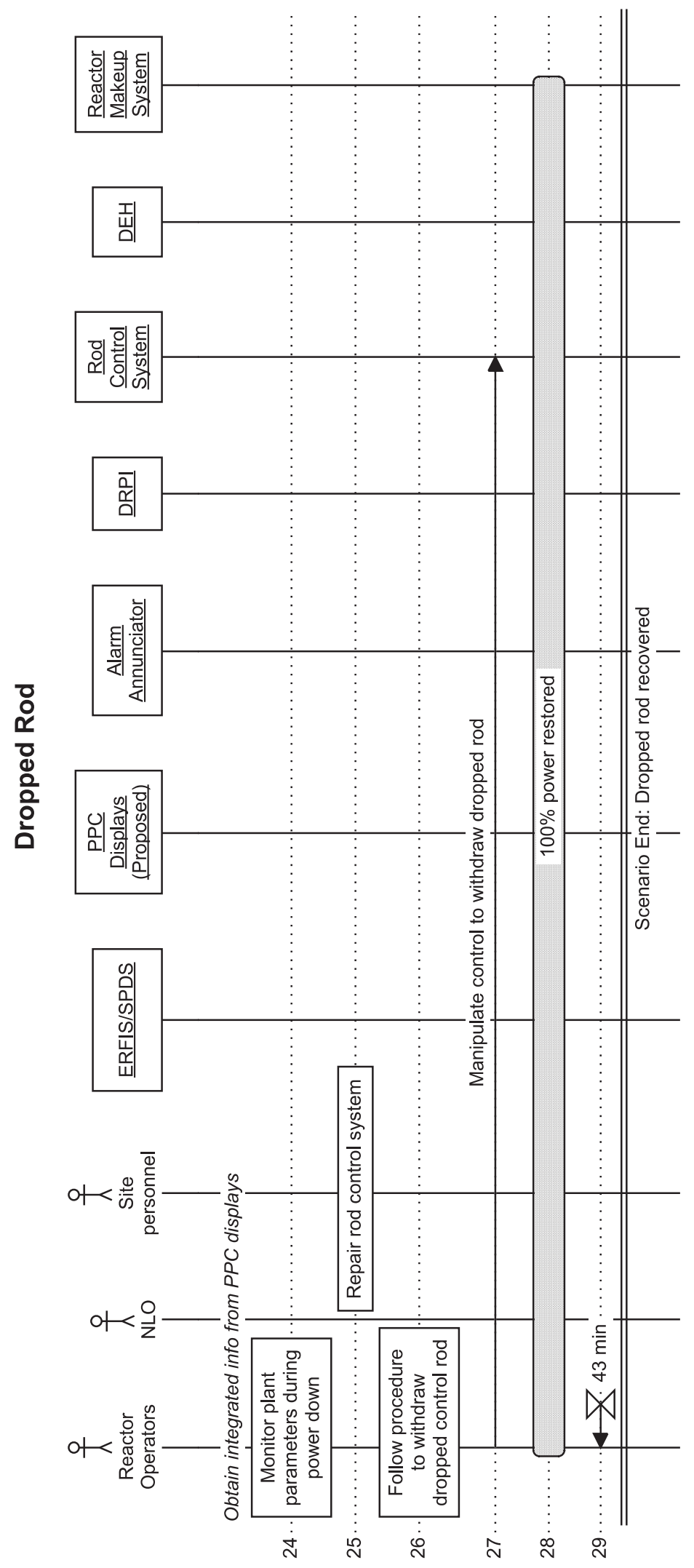




\subsubsection{Combining the FRA/FA and TA Results}

In addition to the identification and analysis of functions and the relative roles of humans and systems, the FRA/FA also helped to create a better understanding of needs associated with the planned system and control room upgrades. It also helped the reactor operators to understand the impact of the upgrades on the their information needs, on ways procedures are conducted, and on their performance, especially response times, reduction of workload, and reduction of human error potential.

An analysis of the identified functions and the associated opportunities for improvement confirmed that those functions were valid for the target system and that the potential function allocation changes must be reviewed during the TA phase.

The verification of the FRA/FA, in combination with the results from the TA, is necessary to achieve the following desired end state of this project:

- Operators are provided with more salient information for specific operational conditions and such information is integrated into the operator's immediate workspace.

This desired state would contribute to improved operator performance through the following means:

- Reduce the need to move around the control room to obtain information from spatially diverse sources;

- Reduce the need for the operator to keep a lot of information in working memory ${ }^{1}$

- Reduce the need to retrieve a lot of information from long-term memory ${ }^{2}$

- Reduce or eliminate the need for mental or hand calculations for accurate diagnoses

- Simplify the mental integration of information.

The TA must produce results that can serve as input requirements for the consideration of technical and human factors trade-offs and the development of specifications for HSI design.

\subsubsection{Compliance with NUREG-0711 Requirements}

The TA method was designed to comply with minimum requirements described in NUREG-0711, Rev. 3, Element 5 ("Task Analysis", page 31) and Element 7 ("Treatment of Important Human Actions", page 43). The following sections describe the means of compliance.

\subsubsection{Important Human Actions to be Addressed by TA}

No probabilistic or deterministic analysis was performed to select important human actions in terms of NUREG-0711 Element 7 (Treatment of Important Human Actions). As explained before, the tasks selected were based on the results of the FRA/FA workshop. Those tasks do not represent the full range of plant operating modes, since they are associated only with the planned PPC functions. In addition,

1 Working memory (sometimes called "short-term memory") is the cognitive system that actively holds multiple pieces of transitory information (like a numerical value) for a short period of time in the mind where they can be manipulated. This involves execution of verbal and nonverbal tasks, such as reasoning and comprehension, and makes them available for further information processing.

2 Information can be retained in long-term memory indefinitely and there are no known limits to the capacity of human longterm memory. 
since the ERFIS does not provide the operator with any control functions, its implementation on the PPC will also be used only to display information.

To comply with the requirements for Important Human Actions, the following assessments were made:

- No tasks were identified as Important Human Actions in terms of the NUREG-0711 definition. The remaining tasks identified do not have negative consequences if performed incorrectly.

- Existing tasks will not be performed significantly differently from predecessor systems.

- The tasks that will be related to monitoring of automated systems are not important to plant safety and there are no automated operator support aids.

- There are no tasks related to identifying the failure or degradation of automation, or implementing backup responses.

- There are no tasks anticipated to impose high demands on personnel, such as time pressure or cognitive or physical workload that would challenge their ability to monitor the plant.

- There are no tasks important to plant safety to be undertaken during maintenance, tests, inspections, and surveillances.

- There are no tasks with potential concerns for personnel safety (such as maintenance tasks performed in the containment).

- The tasks that are new compared to those in a predecessor system, such as information search and navigation functions related to the PPC, have been identified and analyzed in detail during the scenario walkthroughs.

\subsubsection{Selection of Scenarios and Activities to be Performed by Operators}

The graded approach followed during the previous FRA and FA phases was continued during the TA. This included the selection, in collaboration with operators, of scenarios that would focus on significant events, functions, and procedures impacted by the planned PPC upgrade and that would have an influence on operator tasks, the information they would require during specific evolutions, and how current performance challenges might be mitigated by system improvements.

Since the overall plant operations were not being changed by the PPC upgrade, and safety functions and significant human actions were not impacted, the need to provide more scenarios was further limited. This approach also complies with the verification and validation criteria in NUREG-0711, which states:

It is typically not practical to test every potential scenario or set of operational conditions that may be encountered, so some type of sampling is necessary. The objective of Sampling of Operational Conditions is to select a sample of operational conditions that (1) includes conditions representative of the range of events that could be encountered during the plant's operation, (2) reflects the characteristics expected to contribute to variations in the system's performance, and (3) considers the safety and availability significance of HSIs.

Specific criteria considered during the analyses included identification of a range of normal and abnormal plant conditions (e.g., transitions, transients, failures, accidents, I\&C and HSI failures and degraded conditions, etc.) that involve:

- High-risk tasks in which opportunities exist for human error with highly undesirable consequences

- Possible error traps in which operators may make errors affecting system or plant availability, efficient operation, equipment damage, or personal injury

- Parallel activities requiring operations that may interfere with task performance

- Involve the most changes in operator roles and responsibilities 
- Involve increased operator workload and/or limited operator action times

- The greatest opportunity for improved safety and economic performance, such as preventative or corrective actions with highly desirable results

- The potential to reduce the need for knowledge-based tasks by automating all or part of functions, tasks, or subtasks, or by providing procedural support and operator HSI aids.

The activities performed by operators were based on the procedures prescribed for the chosen scenarios described previously.

\subsubsection{Screening Method Used to Select the Tasks}

The task considerations outlined in NUREG-0711 (Table 5-1, p. 33) were applied as part of a graded approach to determine the level of analysis to be performed:

- Alerts and alarms

- Decision-making

- Response requirements

- Teamwork and communication

- Cognitive and physical workload and concurrent tasks

- Need for task support

- Workplace factors, such as ingress, egress and other physical ergonomic factors

- Environmental or physical hazards that may affect operators.

The results of this screening has been captured in the Task Performance Requirements Sections for each plant (see example in Table 13).

Note that during the analyses for all three plants, it was found that many operator tasks and the responses to the task considerations listed above were very similar or even identical across scenarios. This means that there was a significant amount of redundancy in the results from the various scenarios. This served as confirmation of the relevance and sufficiency of the selected scenarios and also demonstrated that the analyses produced human performance information that would be generalizable across control rooms of similar power plants in the fleet.

\subsubsection{Relationship Between Tasks}

The Operational Sequence Analysis was used in conjunction with the narratives and interviews captured during the scenario walkthroughs. The results of the task relationships are summarized in the OSDs (see Figure 4 for an example).

\subsubsection{Task Performance Time Estimates}

Task time requirements were identified at several steps during scenario execution. Feedback was obtained from operators and supervisors on the impact of time constraints on operator performance. The results summarized in this chapter indicated that there were several instances where operators experienced significant pressure to complete a procedure in a given time. The time for such tasks was recorded as part of the scenario walkthroughs and OSDs. Some of the recommendations for future system enhancements were derived from the need to make task time information available to operators in some visual form. In addition to specific task time requirements, the overall task and procedure times were recorded in the scenario summaries and the OSDs included in this report. 


\subsubsection{Workload Estimates}

No specific method was used during the workshop to measure workload. Instead, the analysts relied upon the operators' judgment of their workload. This was based on their assessment of the time pressure experienced during scenarios, the complexity of procedures, the amount of information required to perform actions, the difficulty of obtaining the information, and the consequences of not performing a task correctly or in time.

\subsubsection{Alarms, Information, Controls, and Task Support}

All types and sources of information involved during the scenarios were captured in the scenario summaries (see Table 7 - Table 10). The potential need for task support functions and tools were also identified and recorded.

\subsubsection{Number of personnel needed to complete each task}

The scenario walkthroughs for each plant were conducted with a crew that was considered to be a valid crew complement for the chosen scenarios.

\subsubsection{Knowledge and abilities needed to perform each task}

The scenario summaries include comments about the need for intrinsic skills and knowledge requirements. For example, it was established that for most scenarios, the operators needed to keep a considerable amount of information (e.g., obtained from the panel instruments) in short-term memory. In addition to the ability to follow procedures, considerable experience is needed (declarative knowledge) to perform the scenarios. The exact nature and extent of declarative knowledge was not considered during the workshop.

\subsubsection{Additional Considerations for HFE Aspects of Plant Modifications}

NUREG-0711 recommends the review of prior TA information when plant or system modifications are considered. Since no prior TA for the plants was available during the workshops, the results of the workshop for each will therefore be used to reflect the basic human factors requirements for the PPC modification.

\subsection{Results Summary}

The TA workshops served as follow-on to the FRA/FA workshop, in which reactor operators walked through scenarios relevant to interfacing with the existing instrumentation and controls, including computerized operator support displays like the ERFIS and SPDS. The goal of the FRA/FA workshop was to identify the allocation of control functions between humans and these systems at the plant. The TA workshops built on these findings by identifying opportunities for improvement in information display and controls at the plant, with an emphasis on how these might be applied in the new PPC and TCS.

The TA findings summarized in this chapter describe the operators' interaction with various artifacts in the control room, the information they used to support their tasks, and aspects of system functionality and behavior that affected their performance. The requirements and opportunities for enhancements vary only slightly by task and by plant. A number of significant high-level findings were evident from the 
observations and comments from participants during the three workshops. These findings are summarized across plants in the next section.

\subsubsection{Potential Enhancements as Part of Control Room Modernization}

1. Procedure Support Displays: These would enhance the ability of the operators to move through certain procedures expeditiously. For example, a common set of diagnostic checks is required to step through the Emergency Operating Procedure E-0 that must be followed after a reactor trip. Currently, considerable time is spent finding information in the control room, and the information required by E-0 is not consolidated in one place for efficient diagnosis. These displays would not be automatically invoked, in case an operator was in the process of using a particular screen. Rather, someone like the Procedure Reader would invoke the use of the screen based on which procedure he or she was entering. The displays would be customized for that scenario, aggregating the information that is needed from the various board devices. The different display devices would all be prioritized and optimized as to what information they displayed relative to the scenario. These displays would accommodate the features such as continuous actions and approach to target values, display of those target values, and computations currently performed by the operator on a calculator or mentally performed. They would incorporate the various tables and curves contained in the procedure so that the operator obtained the correct outcome. These displays could also incorporate all the non-certified operator aids that had already been developed at the plants.

2. Information Integration: Important information is not always located in a convenient place for operators to use that information. This could lead to time delays for the reactor operator to locate this information. Worse yet, the operators risk missing important cues because of the out-of-theway location of information. Crucial plant parameters and alarms should be located in a centralized area to minimize the need for the operator to crisscross the control room (the so-called operator ping-pong effect) and to ensure this information is not inadvertently overlooked.

3. Automation of Calculations: A number of calculations (e.g., leak rate or radiation in gallons per day) must be performed manually to support restoring the plant to normal operations. These calculations are time-consuming and error prone, as the operator must identify indications from disparate indicators for the calculations. Required indicators can be consolidated for easier use. Most calculations can be reliably automated to speed operator response and increase operator reliability.

4. Task Timers and Reduction of Concurrent Activities: Complex plant conditions can require the operator to perform multiple simultaneous, continuous actions (e.g., monitor steam generator levels while adjusting boration). The reactor operator must jump between these tasks. Where time is critical in carrying out activities (e.g., borating for a specified number of minutes), task automation could increase operator efficiency. Additionally, task "shot clocks" could help the operator more effectively to track progress across multiple activities.

5. Improvement of Alarm Processing: Operators must mentally prioritize alarms during upset conditions. Multiple instances of alarm flooding were observed in the scenario runs, and operators were not always aware of current ERFIS alarms. The operators had to respond quickly to the most important alarms, making sure to return later to address lower priority items. There is considerable expertise required in this process, and the reactor operators were able to filter incoming alarm information. However, there is a need to improve system processing of alarms to enable better concentration by the reactors operators. Alarm floods serve as distractions for operators and slow the ability of the operator to carry out activities. Integrating these alarms with PPC displays or otherwise cueing them to whatever display they are shown on would be beneficial. Moreover, 
operators expressed the desire to have additional control of the alarms, beyond the simple silence/acknowledge functionality currently found in the control room. The rapid onset of alarms in some upset conditions requires the operator constantly to engage the silence/acknowledge buttons, essentially relegating the operator to one-handed operation, since one hand is engaged in silencing the alarms. One operator suggested it would be useful to have an extended silence button, to silence incoming alarms for several minutes to allow the operator to focus on completing tasks.

6. Manual Logging of Procedure Times: Tasks requiring manual logging by operators (e.g., time when rods drop) could be automated to speed operator response. Such logging functions are for record keeping and rarely serve to help the operator diagnose or resolve an upset condition.

7. Manual Reminders: Operators have goals in mind when performing continuous actions, such as trending a particular plant parameter to ensure it reaches the desired state. Operators currently use Post-It notes to help them remember the desired range at which they will take further action. It is possible for the displays to support such annotation or to automate tasks or notifications to aid operator performance.

8. Summary Status Displays: In many procedures, operators are required to verify a series of plant component statuses are correct, in rapid succession, to proceed to the next action step. These verifications often require the operator to traverse the full length of the control boards to check discrete gauges and status points. A summary of these statuses (e.g., a "green" annunciator on a PPC (DCS) display, could indicate to the operator that all such statuses have been verified as correct for the operator to proceed to the action step. The time to conduct these verifications is currently extended by the time required for three-way communication for each verification.

9. Job Aids: The plant has developed a number of computer-based operator job aids, such as computational functions in Excel. These job aids have not been certified in a manner that operators can take credit for them. Therefore, the results have to be validated through certified control room information. These job aids should be evaluated for certification and inclusion into the PPC functions.

10. Graphical Vessel Displays: Reactor Vessel Level Indication System (RVLIS) is a function of the SPDS. It would be helpful to have a reactor vessel outline drawing that graphically presented levels and trends.

11. Control Room Ergonomics: The ergonomic allocation and location of input devices (i.e., viewing angles, heights and sight lines), particularly the arrangement of keyboards and their locations should be considered.

\subsection{Conclusion and Recommendations}

This TA phase of the fleet-wide control room modernization project has demonstrated that the present state of systems in all three control rooms place unnecessary demands on operators' ability to perform many simultaneous activities with high accuracy and high reliability over extended periods of time. The need for extreme vigilance, accuracy and situation awareness is necessary because of the current inability of plant systems to perform relatively simple, routine functions such as leak rate calculations, trending of system performance, detecting and displaying of deviations and exceptions, or enabling operators to access any item of information rapidly from central locations in the control. In addition, the current design of the control systems for all three plants provides very little high-level plant performance information. This requires operators to operate the plant from data obtained from discrete indicators and to perform certain functions that could be performed easier, quicker and more accurately by the system. The cognitive task of integrating and translating discrete items of data into salient and useful operational information requires extensive training, practice and retraining. Operators are highly skilled and reliable, 
but they continually face high mental workloads and the stress of maintaining situation awareness for extended periods of time under varying operational conditions. The conclusion is therefore that any improvement in the human factors in work environments in nuclear power plants, especially control rooms, should receive serious consideration.

The TA workshops at the three plants were aimed at identifying and analyzing the specific tasks that need to be performed by operators to accomplish the requirements of specific as well as general operational conditions associated with the planned PPC and technical support center (TSC) upgrades. The workshops identified many operator tasks and performance characteristics that were very similar or identical across scenarios. The redundancy in results obtained in this manner served as confirmation of the following:

- The graded approach to performing the TA was appropriate and a valid method to achieve the objectives of the bounded Human Factors Engineering Plan.

- The selected scenarios were relevant and suitable to identify and describe operator tasks and performance requirements for specific plant conditions.

- The TA results demonstrated that human performance information would be generalizable across control rooms of similar power plants in the fleet (e.g., based on similarities between Plant A and Plant C).

- The results obtained from the FRA/FA and TA workshops demonstrated the validity of the INL HFE methodology. It also demonstrated how the logical progression of analysis phases adds significant value to the quality of information obtained.

- The successive workshops allowed the project team to refine the methodology so that unnecessary steps could be eliminated, while maintaining the quality of results. As indicated by the increasing redundancy of information (which could be regarded as diminishing return on invested effort) and the time constraints faced with Plant $\mathrm{C}$, it was shown that it is possible to combine the FRA/FA and TA workshops and to reduce the number of scenarios necessary to obtain useful results.

Consolidated recommendations for PPC and TCS enhancement from the three workshops and comments received from participants are found in Table 15. The identified areas for task improvement described in this chapter will serve as the starting point for the next phase of the HFE process. However, it must be emphasized that TA results cannot be translated directly into HSI design requirements without further analysis of information architectures and the specific functional and technical characteristics of the systems to be upgraded. This further analysis, including detailed specification and conceptual design work, should form the first phase of HSI Design, which will be treated in a future reference plan report. 
Table 15. Human Factors Recommendations for PPC and TCS Upgrades.

\begin{tabular}{|l|l|}
\hline Operator task requirement & Potential task support concept \\
\hline $\begin{array}{l}\text { Improve ability to detect deviations and } \\
\text { exceptions, perform diagnoses and } \\
\text { reduce need to mentally integrate } \\
\text { discrete data points. }\end{array}$ & $\begin{array}{l}\text { Future PPC displays should provide scalable and operator-configurable } \\
\text { trends graphs for all critical time-based performance parameters } \\
\text { identified in this report. }\end{array}$ \\
\hline $\begin{array}{l}\text { Improve accessibility and readability of } \\
\text { information. }\end{array}$ & $\begin{array}{l}\text { Graphic displays (analog and digital, as appropriate) should be available } \\
\text { for indications that are currently difficult to read, such as turbine control } \\
\text { indications, generator indications, tank volumes and levels, valve } \\
\text { positions, etc. }\end{array}$ \\
\hline Improve information accessibility. & $\begin{array}{l}\text { Flat panel displays should be provided in locations as near to the } \\
\text { operator's central work area as possible. As many displays should be } \\
\text { provided as allowed by available space on the existing panels. }\end{array}$ \\
\cline { 2 - 3 } & $\begin{array}{l}\text { Information architectures (ERFIS, SPDS, etc.) should be designed to } \\
\text { provide a logical, intuitive, easily navigable structure. }\end{array}$ \\
\hline Improve situation awareness & $\begin{array}{l}\text { Provision should be made on new visual display units (VDUs) for } \\
\text { operator-configurable as well as automatic task timers ("shot clocks") } \\
\text { for time-critical actions. Where appropriate, such timing information } \\
\text { could also be integrated into relevant trend plots. }\end{array}$ \\
\hline $\begin{array}{l}\text { Reduce burden on working memory and } \\
\text { reduce error potential. }\end{array}$ & $\begin{array}{l}\text { Provide operator-configurable overview displays and high-level } \\
\text { performance and status displays. }\end{array}$ \\
\hline $\begin{array}{l}\text { Reduce need for mental or manual } \\
\text { calculations, reduce time required for } \\
\text { diagnosis, and reduce error potential. }\end{array}$ & $\begin{array}{l}\text { Provide calculated values (e.g., leak rates, rate of change) integrated into } \\
\text { all relevant displays. Include options for operators to configure } \\
\text { parameters. }\end{array}$ \\
\hline $\begin{array}{l}\text { Improve procedure following and reduce } \\
\text { need for procedure attachments (Hard } \\
\text { Cards). }\end{array}$ & $\begin{array}{l}\text { Provide "procedure-based" displays that automatically integrate selected } \\
\text { procedure information in trends, rate calculations, exception displays, } \\
\text { overview displays, etc. }\end{array}$ \\
\hline
\end{tabular}




\section{NEXT STEPS: DESIGN, VERIFICATION AND VALIDATION, AND IMPLEMENTATION}

\subsection{Introduction}

After the Planning and Analysis phase of NUREG-0711 is completed, as discussed in Chapters 2-4, NUREG-0711 prescribes three further phases: Design, Verification and Validation, and Implementation and Operation. This chapter scopes concrete next stages to design, validate, and implement the PPC and TCS at the three plants. The scope of the continuation of the HFE Program described in this chapter is limited. The scope includes the following:

- Main control room HFE HSI design issues. HFE issues related to the technical support center (TSC), emergency operations facility (EOF), remote shutdown facility (RSF), and local control stations (LCSs) are considered out of scope, except for displays, controls and annunciators that may be relocated to or from the MCR.

- HSIs involved in maintenance activities are considered in this HFE Program, if their use is related to MCR operations. For example, if a maintenance technician uses an HSI to support troubleshooting and that HSI is also available to a MCR operator to support cooperation between maintenance and operations, then activities related to this HSI are within the scope of the HFE Program.

The Design, V\&V, and Implementation and Operation phases have sub-elements described in NUREG0711. For the Design phase, in keeping with a graded approach, this chapter focuses only on HSI Design, excluding two sub-elements:

- Procedure Development — which is not required, since the new DCS will directly support existing procedures;

- Training Program Development - the objectives, requirements, and frequency of which are not changed as a result of the modernized PPC, although it is expected that understanding and using the HSI will be included in the training, as will skills associated with operating the plant in the event of DCS failure. Again, these do not constitute a change in the training regimen, just a transition in training from the existing PPC to the new DCS.

This chapter includes all elements of the V\&V (i.e., Human Factors Verification and Validation). It includes the Design Implementation element of the Implementation and Operation phase. It omits:

- Human Performance Monitoring - which represents a long-term activity aimed at maintaining the system. Should deficits be detected through long-term human performance monitoring, the Design phase should be revisited. If satisfactory human performance cannot be maintained through training, the Human-System Interface Design element should be revisited.

Detailed information is provided in this chapter regarding the planning, objectives, approach, scheduling, and deliverables for each element that is included. Section 5.2 presents the HSI design activities. The $\mathrm{V} \& \mathrm{~V}$ element is provided in Section 5.3. Section 5.4 contains the design implementation element. An overall plan for carrying out these phases is included in Section 5.5. 


\subsection{Composition of the Design Team}

NUREG-0711, Rev. 3, has an appendix that discusses the composition of the team that is required to carry out a human factors engineering program. Not all personnel identified in NUREG-0711 are relevant to the design phases addressed in this report. The relevant personnel for PPC and TCS modernization are:

- Technical project management

- Systems engineering (Design engineering)

- Instrumentation and control engineering

- Architect engineering

- Human factors engineering

- Plant operations

- Computer system engineering

- Personnel training

- Procedure writers

- DCS vendors

NUREG-0711 does not expressly call out Simulator engineers (although they are often included in training organizations at NPPs). Simulator engineers are uniquely important for the Planning and Analysis phases and V\&V.

\subsection{HSI Design Element Activities}

As described in NUREG-0711, Rev. 3, "The HSI design process represents the translation of function and task requirements into HSI characteristics and functions." This section explains how previous work performed in the Planning and Analysis phase feeds into the actual design of the HSI. This section also illustrates the process by which existing PPC displays may be migrated to the new DCS platform as well as the process by which new functionality can be introduced to the control room. In addition, an existing system on the panel, the TCS, is being converted to a DCS, and this section contains guidance to ensure the new design is successful.

As depicted in Table 16, the elements of the Planning and Analysis phases each provide key information that is used in the design of the new HSI for the control room. These pieces of information are combined with a specification for each HSI display used in the DCS. The specification may be developed according to the sections below, corresponding to migrated vs. new HSIs. A key assumption is that the DCS HSI will take the place of existing displays or standard instrumentation and controls on the control boards. This discussion does not consider additional topics relevant to migrating from the control panels to workstations or other advanced HSIs beyond the control boards.

\subsubsection{HSI Specification}

Each HSI display specification should include a general name of the display (corresponding to plant naming and numbering conventions), a description of the function of the display, a description of the placement of the display (e.g., some displays may be statically located, while others may be pulled up from any DCS display), assumptions regarding the hardware (e.g., size and resolution of display), information about the control mechanism (e.g., soft controls using a touchscreen vs. mouse or keypad control), and version information. Additionally, the specification should address the required information 
Table 16. Use of HFE Program Elements in HSI Design.

\begin{tabular}{|l|l|}
\hline HFE Program Element & Use in the HSI Design \\
\hline Operational Experience Review & $\begin{array}{l}\text { Lessons learned on previous system use and } \\
\text { identification of important human actions }\end{array}$ \\
\hline $\begin{array}{l}\text { Functional Requirements Analysis/Function } \\
\text { Allocation }\end{array}$ & $\begin{array}{l}\text { Opportunities for automation of displays and } \\
\text { system execution; required role of operators in } \\
\text { controlling the system }\end{array}$ \\
\hline Task Analysis & $\begin{array}{l}\text { Information and tools required by operators to } \\
\text { support task execution }\end{array}$ \\
\hline HSI Style Guide & $\begin{array}{l}\text { Requirements for controls, navigation, visual } \\
\text { presentation, and other HSI elements }\end{array}$ \\
\hline
\end{tabular}

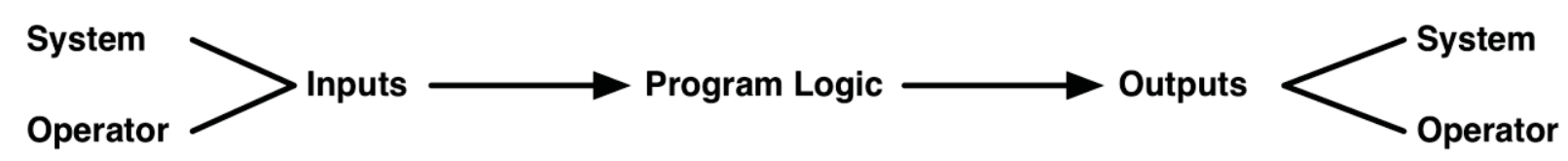

Figure 5. Required Information for DCS Display Specification.

found in Figure 5, namely the relationship between operator/system inputs, the program logic, and the operator/system outputs. The system inputs (e.g., temperature at a certain sensor point) and outputs (e.g., valve close signal) may not in all cases be displayed to the operator, but their background use should be clearly documented in the specification. The specification should also feature documentation about any design considerations from the Planning and Analysis phases depicted in Table 16 that influenced the design. The design background information is crucial should later design modifications or license review be required.

\subsubsection{Migrating an Existing HSI Display}

A number of displays - most notably the ERFIS and SPDS - are slated for migration from the existing platforms to the new DCS platform used by the utility. These displays have been demonstrated to be of use to operators, and it is desirable to carry those displays forward to the new DCS. While no new functionality is required for these legacy displays, an effective migration needs to consider the characteristics of the DCS vs. the predecessor system. Relevant factors include:

- Navigation: If the DCS has a standardized navigation scheme, the legacy displays may not conform to that standard. For example, ERFIS displays may feature primarily command-line execution, whereas the navigation of the DCS is mainly menu driven. This disparity must be reconciled. Fortunately, the decision how to handle navigation is a one-time decision that can be applied across 
the entire suite of ERFIS displays, not piecemeal for individual ERFIS displays. The general navigation solution should be complemented by display-specific navigation, e.g., where the display fits in menus or navigation groupings.

- Display Characteristics: The DCS displays will likely be higher resolution and feature greater color depth than the predecessor systems, which may require some scaling conventions. Moreover, the DCS may feature reserved areas (e.g., designated alarm areas or navigation panes) that may not conform to the layout of the existing displays. The legacy displays may require additional updates to conform to the current DCS HSI style guide. These display characteristics will need to be considered for each legacy display, although a few general display migration rules should suffice for the majority of displays.

- Additional Functionality: For most purposes, the addition of features to legacy displays should be minimized. However, there may be some features that are required for continuity with newer DCS displays. For example, alarm functionality not found in the legacy PPC displays may be desirable or even expected to harmonize the look and feel of the displays. The decision must be made to what extent the legacy displays look or behave differently than newer DCS displays. It is preferable not to have multiple HSI conventions and styles within the DCS. However, the cost of adding or harmonizing features to legacy displays must be considered. Note that operators will tend to prefer displays with which they are familiar. An initial preference to retain the look and feel of legacy displays should be evaluated after operators have opportunity to gain experience with the new DCS. Also note that core functionality of a legacy HSI display should in most cases remain the same despite any aesthetic upgrades.

Table 17 provides a step-by-step list of questions to consider in the migration of legacy displays to the new DCS. The decision process behind these questions should be documented with the display specification. This checklist should be used to help finalize the design specification for each migrated HSI display. Following development of the specification, the HSI displays should be prototyped to verify appearance, functionality, and completeness. Each migrated HSI display should be reviewed by operators prior to performing the formal V\&V activity. Designs that do not meet initial operator satisfaction should be iterated to improve the design. Documentation of the migrated design should explain how changes are consistent with earlier HSIs and the plant's Safety Analysis Report.

\subsubsection{Designing New HSI Displays}

The FRA/FA and TA workshops have identified new functionality that would be advantageous to the operators in the modernization of the PPC and TCS (see Section 4.2.1 for a discussion). Example new functions that were identified include but are not limited to:

- Procedure Support Displays: These can be called up to support operators walking through particular commonly used or complex procedures (e.g., a display to bring up plant parameters required to step through emergency operating procedure E-0)

- Automated Calculations: Many required parameters currently have to be calculated manually by operators from separate and sometimes distally located indicators in the current control room configuration (e.g., leak rate calculation)

- Shot Clocks: These help the operator keep track of time required for continuous action steps, including multiple simultaneous continuous actions

- Prioritized Alarms: These help the operator to focus on the most safety critical tasks at hand. 
Table 17. HSI Design Migration Checklist.

1. Do any lessons learned from the Operational Experience Review apply to this display, and are any changes required as a result?

a. If YES, what changes are required? If significant changes ${ }^{3}$ are required, follow the process outlined in Section 5.3.3 on designing new HSI displays.

2. Is any additional functionality suggested by the Functional Requirements Analysis or Function Allocation?

a. If YES, what changes are required? Should the changes be made to this display, or should a new display be created? Follow the process outlined in Section 5.3.3 on designing new HSI displays.

3. Is all required information identified in the Task Analysis present in the display to support task execution?

a. If YES, what changes are required? If significant changes are required, follow the process outlined in Section 5.3.3 on designing new HSI displays.

4. Does the existing display adhere to the present HSI Style Guide?

a. If NO, what changes are required? Do the graphics translate or scale to the new DCS displays? Does navigation require updates? Are there conflicts (e.g., reserved areas on the DCS displays) between the existing display and the DCS? If significant changes are required, follow the process outlined in Section 5.3.3 on designing new HSI displays.

5. Are any required changes to the existing displays universal? In other words, can changes made to one legacy display be used as a template for other displays?

a. If YES, document these changes (e.g., how to switch from command-line navigation to menu navigation) as an addendum to the HSI Style Guide, specifically as an HSI Migration Style Guide. This should eliminate the need to redesign each legacy display according to Section 5.3.3.

b. If an HSI Migration Style Guide is available, follow it. If there are any required exceptions to this style guide, note them.

These new features should be developed in accordance with a standard user-centered design method such as ISO 9241-210 (2010), Ergonomics of Human-System Interaction-Part 210: Human Centered Design for Interactive Systems, and ISO 9241-11 (1998), Ergonomic Requirements for Office Work with Visual Display Terminals (VDTs) - Part 11: Guidance on Usability. An example approach tailored for DCS design can be found below in Figure 6. The approach has five basic steps:

1. Identify the desired features and functions of the DCS display - whereby insights are extracted from the Operational Experience Review (to the extent there may be deficits in the existing HSI), the FRA/FA, and the TA. There should be a clearly documented need for the new functionality as demonstrated by an existing performance deficit (e.g., as a cumbersome or error-inducing HSI) or the opportunity for operator performance improvement (e.g., increased reliability through automation or improved operator response time). While operator desires for new features may be considered, the basis for new features and functions should remain grounded in opportunities for improved reliability, safety, and performance.

2. The desired features and functions are turned into a specification. The HSI display specification should conform to the requirements outlined in Section 5.3.1. This display specification should conform to the HSI Style Guide for the DCS.

\footnotetext{
${ }^{3}$ Significant changes to the HSI display would be those that change the actions the operator takes or the information provided to the operator by the display.
} 


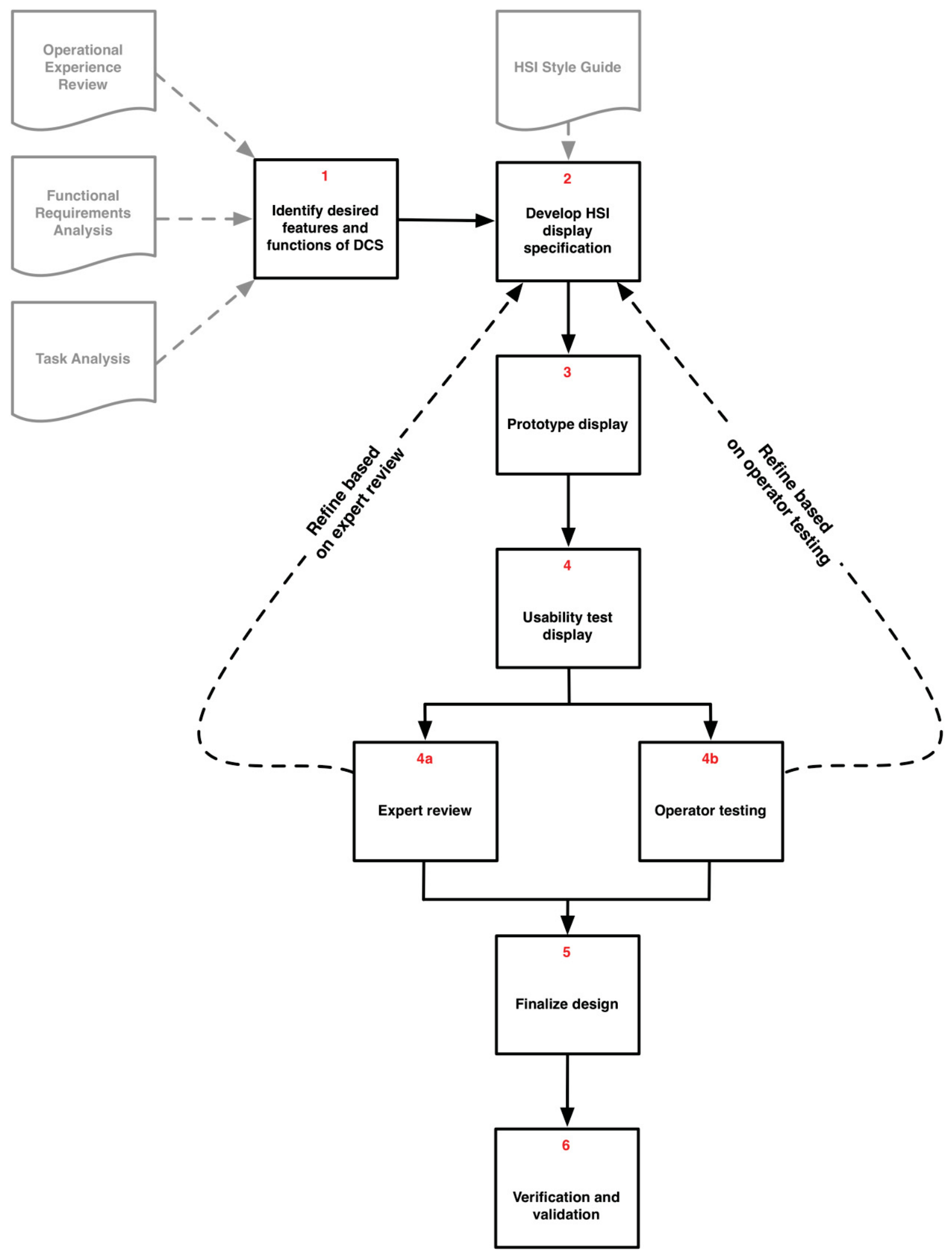

Figure 6. Flow Diagram for Developing New HSI Displays for DCS. 
3. The specification is prototyped to a degree suitable for evaluation. The prototype can be as simple as a line sketch of the interface or involve using the DCS graphics development tools to create an early version of the final implemented DCS. The prototype should contain sufficient fidelity such that dimensions and colors can be depicted accurately. If the native DCS environment is used in the prototype, it is not necessary to enable all functionality. The prototype will be evaluated, and it is important that the prototyping phase not be considered the end development and deployment stage. The prototype may be discarded in favor of better designs, once the usability testing is complete.

4. The prototype is usability tested. Usability testing is the process of assessing the degree to which the designed system can be used effectively by the target user. Success metrics range from user satisfaction to user performance. In the case of the usability evaluation of the DCS displays, the goal is foremost to ensure that operators understand the HSI elements and also can operate the HSI, from navigating between different displays in the DCS to controlling parts of the plant using the DCS. The usability evaluation is ideally formative, meaning it is used not only to verify the usability of the designed system but also to help specify the design in an iterative fashion. There are two accepted ways of usability testing:

a. Expert Review: In this approach, subject matter experts in human factors, nuclear operations, or control systems review the HSI. This review may follow specific usability criteria called heuristics or provide an overall impression of how the HSI would be used and any deficiencies they might note. Expert reviews are especially useful early in the design phase, when a more detailed, full-scale V\&V will be conducted later in the development cycle.

b. Operator Testing: Such testing can range from walkthroughs with nonfunctional mockups to scenario testing using fully functional prototypes. The level of fidelity and functionality is a product of the resources of the design team and the degree to which the new functionality diverges from current plant operations. Note that operator testing at this stage will typically focus on the DCS HSI alone and not in the overall context of the control room. Integrated system validation (ISV) - testing of the new DCS in the full control room-occurs at the $\mathrm{V} \& \mathrm{~V}$ phase.

Results from the usability testing phase should be used to refine the design. If there are design deficiencies, the design should be revised and the process iterated starting at Step 2.

5. The design is finalized. Once the prototype has been evaluated and it has been determined that the HSI can be used successfully and safely by operators in the control room, the design specification and supporting documentation are assembled. This information is used as the basis of implementation and should be retained for licensing support. Additionally, it is not anticipated that new HSI functionality incorporated into the control room would require a change in plant operating procedures. As the design is finalized, the adequacy of existing procedures should be evaluated and documented.

6. The finalized design will be used in the $\mathrm{V} \& \mathrm{~V}$ phase, which is documented in the next section.

\subsection{Human Factors Verification and Validation of the HSI}

The HSI design process described in Section 5.3 encompasses many of the HSI testing requirements for V\&V outlined in NUREG-0711. In fact, a general user-centered design approach like Section 5.3 is explicitly endorsed in NUREG-0711, Rev. 3. The specific phase of V\&V that must be conducted independent of usability testing is integrated system validation (ISV). The steps for an ISV on the modified or new HSIs for PPC and TCS encompass the following steps: 
1. The prototyped system is implemented in a fully functional variant in the full-scope control room simulator. The actual DCS should be embedded in the simulator to minimize the need for later detailed analysis of differences between the as-tested vs. as-deployed system. As such, the DCS should follow careful software and hardware quality assurance requirements as part of the ISV.

Note that a glass-top simulator such as the HSSL using the underlying plant model from the training simulator may serve as a surrogate for the actual plant training simulator. This process can avoid the need to physically modify the training simulator (e.g., change hard panels to introduce displays) until the implementation phase. Having a facility separate from the training simulator that can support ISV has a further benefit. It avoids potential conflicts between training for the plant as it is vs. the plant as it will be once modified.

2. A representative sample of scenarios are selected to walk through the new DCS HSIs with operators. These should be scenarios that encompass actual use of the DCS, test operator knowledge, test operator interactions with each other in the control room, and represent potential accident sequences. Note that the scenarios previously used in the FRA/FA and TA workshops fulfill these criteria. The same scenarios that were run previously can be run during the $\mathrm{V} \& \mathrm{~V}$ phase. These scenarios thereby also serve to benchmark operator performance before and after the new DCS HSI.

3. The DCS should be pilot tested with a group of operators or qualified personnel (e.g., not-yet-licensed reactor operators, qualified trainers, recently retired reactor operators) to ensure the proper functioning of the system.

4. Licensed reactor operators are trained on the use of the new DCS HSIs. A stand-alone DCS HSI training program will be developed in cooperation with the training organization. In addition, the scenarios will be reviewed by trainers and procedure writers to ensure that the operating procedures do not require modifications as used in conjunction with the new DCS.

5. Operators perform the selected scenarios using the new DCS HSI for PPC and TCS. A combination of systems engineering, HFE, and training personnel oversee the scenario walkthroughs to ensure:

- The DCS implementation functions per the design specification.

- The operators are able to complete the scenario tasks successfully (i.e., correctly, completely, within time requirements, and without confusion or misunderstandings) using the new DCS. HFE personnel will assess situation awareness and workload to ensure these are within acceptable bounds.

More than one set of operators should walk through the scenarios, and the order of the scenarios should be randomized to ensure performance on particular scenarios doesn't simply reflect learning effects.

6. The results of the ISV should be documented. Any deficiencies (e.g., human engineering discrepancies) should be resolved, and those resolutions should be documented. Significant deficiencies should follow the HSI Design process in Section 5.3, although in most cases, a repeat of the entire ISV may not be necessary, assuming usability testing of redesigned HSIs is conducted. 


\subsection{Design Implementation of the DCS HSI}

As outlined in Section 5.4 of this chapter, the DCS HSI is actually completed and tested as part of the ISV process. A final phase involves installing the new DCS and HSI. There are several stages to this installation:

1. The underlying DCS is installed in the plant simulator and plant. This installation includes any required vendor hardware for the DCS, any architectural backbone upgrades necessary to send and receive information between the DCS and plant sensors and controls, and any configuration protocols and simulator upgrades necessary to send and receive information between the DCS and the simulator. The DCS may be installed and run in background mode ahead of the HSI deployment, which provides a window in which to verify the DCS configuration integrity prior to HSI deployment.

2. The DCS HSI for PPC and TCS is deployed in the control room simulator for training purposes.

3. Operators are trained on the DCS HSI for the PPC and TCS. This training includes DCS fundamentals (operation, navigation, etc.) and specific training on the PPC and TCS. Training should include backup operations in the event of the failure of the DCS. Note that it may be possible to maintain both a legacy and DCS HSI in the training facilities until the deployment of the DCS HSI in the main control room. Glass-top simulators available at plants as classroom training aids would be ideal for maintaining a second configuration of the PPC and TCS as long as needed. All operators should receive the DCS training prior to HSI deployment in the main control room.

4. The PPC and TCS DCS HSI are deployed in the main control room. This will involve removing some existing I\&C from the hard panels for the TCS and replacing legacy PPC displays and hardware elsewhere. This task is best accomplished during plant outage, as both systems are integral to plant operations. As such, the target date for final deployment of the PPC and TCS DCS HSI will likely need to be calibrated to correspond with a scheduled refueling outage at the plant.

With separate DCS backbone and DCS HSI deployments, the deployment of the DCS would logically span a period between two scheduled outages at the plant. It is, however, possible to compress this cycle. The DCS, including both the backbone and the HSI, may be deployed in a single setting. Alternately, portions of the DCS backbone may be installed piecemeal, without major obstruction to regular plant operations.

\subsection{Sample Plan for Design, V\&V, and Implementation Phases}

This final section provides a sample plan that encompasses the design, $\mathrm{V} \& \mathrm{~V}$, and implementation phases for the DCS HSI. NUREG-0711 calls for detailed implementation plans for each phase, and this section may serve as a template for a plant-specific implementation of the PPC and TCS modernization at the plants covered in this report. This section should also serve as a useful guide for aligning subcontractors and their statements of work to the upgrade project.

\subsubsection{Assumptions}

This sample plan assumes the vendor for the DCS has been selected. This plan also assumes that necessary infrastructure upgrades to the main control room have been implemented and that the DCS is in place or could be deployed outside of a refueling outage. This plan also assumes that the requisite 
planning and analysis phases of NUREG-0711 have been conducted, as is the case with the plants covered earlier in this report. This plan further assumes that the requisite HSI design work has been completed for the TCS. It also assumes that a glass-top simulator is available to conduct ISV activities independently of the plant training simulator, either at the plant or at another facility. If these assumptions do not hold, additional activities and time must be built into the plan.

\subsubsection{Participants}

The design and deployment of the DCS HSI will require a variety of plant and outside personnel. The table below identifies the primary stakeholders required to carry out the plan.

Table 18. Participants in DCS Modernization.

\begin{tabular}{|l|l|}
\hline Plant Personnel & $\underline{\text { Non-Plant Personnel/Subcontractors }}$ \\
PM Technical project management & DC DCS vendor \\
IC Instrumentation and control engineering & HS HSI vendor \\
AE Architect engineering & HF Human factors engineering (e.g., INL) \\
PO Plant operations & \\
CS Computer system engineering & \\
PT Personnel training and simulator operations & \\
PW Procedure writers & \\
\hline
\end{tabular}

\subsubsection{Project Plan}

A sample project plan for a 15-month design, $V \& V$, and implementation of the new DCS HSIs is presented in Table 19. This project plan includes the duration for the project phases. The exact level of effort for each participant (listed in the personnel column) will need to be determined based on available staff to support each activity. Note that some activities like Tasks 2 and 3 to migrate existing PPC displays to the new HSI will take more staff hours to complete due to the multiple ERFIS displays than it will take to develop a few new displays in Tasks 7 and 8 . These are assumed to be parallel activities, with resources divided between the tasks accordingly. 
Table 19. Project Plan for Design, V\&V, and Implementation for DCS HSI in the Main Control Room.

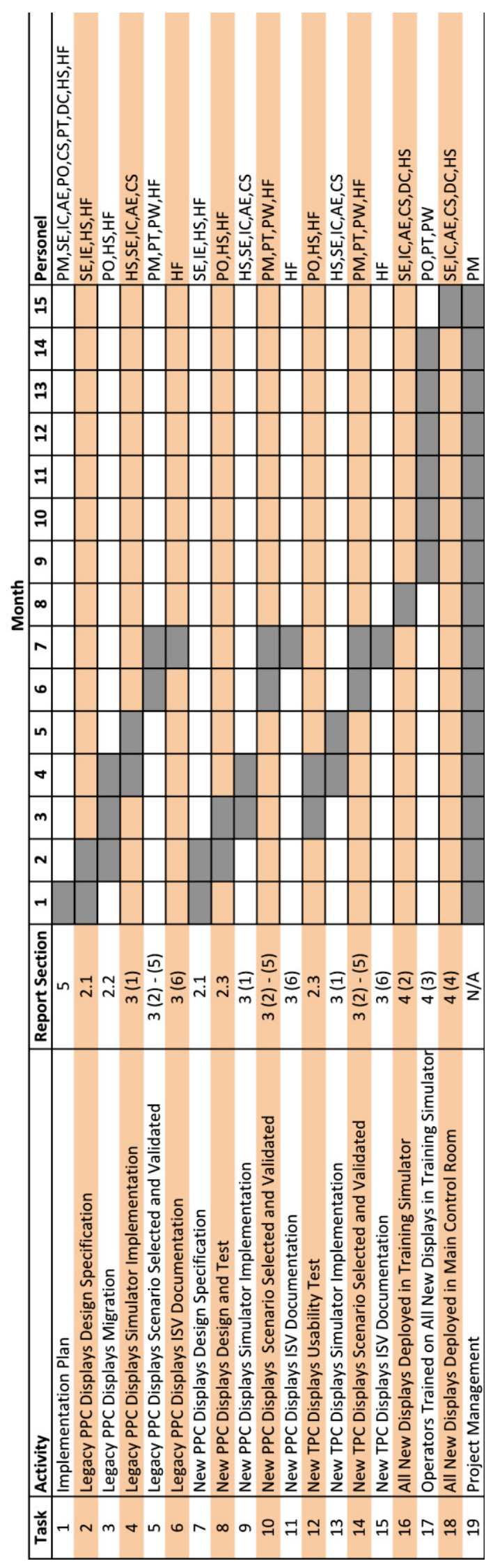




\section{REFERENCES}

Boring, R.L., Agarwal, V., Joe, J.C., and Persensky, J.J. (2012). Digital Full-Scope Mockup of a Conventional Nuclear Power Plant Control Room, Phase 1: Installation of a Utility Simulator at the Idaho National Laboratory, INL/EXT-12-26367. Idaho Falls: Idaho National Laboratory.

Boring, R., Agarwal, V., Fitzgerald, K., Hugo, J., and Hallbert, B. (2013). Digital Full-Scope Simulation of a Conventional Nuclear Power Plant Control Room, Phase 2: Installation of a Reconfigurable Simulator to Support Nuclear Plant Sustainability, INL/EXT-13-28432. Idaho Falls: Idaho National Laboratory.

Electrical Power Research Institute. (2005). Human Factors Guidance for Control Room and Digital Human-System Interface Design and Modification, 1010042. Palo Alto: Electrical Power Research Institute.

Electrical Power Research Institute. (2011). Human Factors Engineering Training Course for Utilities Involved in New Power Plant Designs, Construction and Operation, 1023011. Palo Alto: Electrical Power Research Institute.

Institute of Electrical and Electronics Engineers. (2004). IEEE Recommended Practice for the Application of Human Factors Engineering to Systems, Equipment, and Facilities of Nuclear. Power Generating Stations and - Other Nuclear Facilities, IEEE 1023. New York City: Institute of Electrical and Electronics Engineers.

International Standards Organization. (1998). Ergonomic Requirements for Office Work with Visual Display Terminals (VDTs) —Part 11: Guidance on Usability, ISO 9241-11. Geneva: International Standards Organization.

International Standards Organization. (2010). Ergonomics of Human-System Interaction-Part 210: Human Centred Design for Interactive Systems, ISO 9241-201. Geneva: International Standards Organization.

O'Hara, J.M., Higgins, J.C., Fleger, S.A., and Pieringer, P.A. (2012). Human Factors Engineering Program Review Model, NUREG-0711. Washington, DC: U.S. Nuclear Regulatory Commission.

Ulrich, T., Boring, R., Phoenix, W., DeHority, E., Whiting, T., Morrell, J., and Backstrom, R. (2012). Applying Human Factors Evaluation and Design Guidance to a Nuclear Power Plant Digital Control System, INL/EXT-12-26787. Idaho Falls: Idaho National Laboratory.

U.S. Nuclear Regulatory Commission. (1983). A Methodology for Allocating Nuclear Power Plant Control Functions to Human or Automatic Control, NUREG/CR-3331. Washington, DC: U.S. Nuclear Regulator Commission.

U.S. Nuclear Regulatory Commission. (1992). Operating Experience Feedback Report - Human Performance in Operating Events, NUREG-1275, Volume 8. Washington, DC: U.S. Nuclear Regulator Commission.

U.S. Nuclear Regulatory Commission. (1996). HFE Insights For Advanced Reactors Based Upon Operating Experience, NUREG/CR-6400. Washington, DC: U.S. Nuclear Regulator Commission.

U.S. Nuclear Regulatory Commission. (2000). Guidance for Implementation of 10 CFR 50.59, Changes, Tests, and Experiments, Regulatory Guide 1.187. Washington, DC: U.S. Nuclear Regulator Commission.

U.S. Nuclear Regulatory Commission. (2005). Operating Experience Feedback Report - TurbineGenerator Overspeed Protection Systems, NUREG-1275, Volume 11. Washington, DC: U.S. Nuclear Regulator Commission. 